\begin{tabular}{cc|c}
\hline Tar. Bil. Der. & Tarım Bilimleri Dergisi & Journal of Agricultural Sciences \\
& $\begin{array}{c}\text { Dergi web sayfası: } \\
\text { www.agri.ankara.edu.tr/dergi }\end{array}$ & Journal homepage: \\
& www.agri.ankara.edu.tr/journal
\end{tabular}

\title{
Yakın Kızıötesi Yansıma Spektroskopisi (NIRS) ile Bazı Toprak Özelliklerinin Belirlenmesi
}

\author{
Hüseyin ŞENOL ${ }^{a}$, Mesut AKGÜL ${ }^{a}$ \\ ${ }^{a}$ Süleyman Demirel Üniversitesi, Ziraat Fakültesi, Toprak Bilimi ve Bitki Besleme Bölümü, Isparta, TÜRKIYE
}

\section{ESER BILGİSi}

Araştırma Makalesi - Tarım Teknolojileri DOI: 10.1501/Tarimbil_0000001208

Sorumlu Yazar: Hüseyin ŞENOL, E-posta: huseyinsenol@sdu.edu.tr, Tel: +90(246) 2118607

Geliş Tarihi: 24 Mayıs 2012, Düzeltmelerin Gelişi: 27 Aralık 2012, Kabul:10 Ocak 2013

\begin{abstract}
ÖZET
Modern toprak sinıflama sisteminde, toprak parametrelerinin arazi şartlarında tespit edilemeyen özelliklerinin laboratuvar şartlarında belirlenmesine gereksinim vardır. Elde edilen sayısal veriler toprak oluşum hipotezleri ile kontrol edilip yorumlanabilir. Bu şekilde elde edilen parametreler yardımıyla toprakların oluşum süreçleri yorumlanmakta ve bu veriler toprakların sınıflandırılmasında kullanılabilmektedir. Toprağın fiziksel ve kimyasal özelliklerini belirlemek amacı ile çok çeşitli analiz metotları bulunmaktadır. Özelliklerin belirlenmesinde kullanılan yöntemler zaman alıcı ve pahalı olmakla birlikte, son dönemlerde NIRS (Yakın kızılötesi yansıma spektroskopisi) gibi alternatif yöntemler üzerinde çalışmalar yapılmaktadır. NIRS fiziksel anlamda materyale zarar vermeyen, hızlı, tekrarlanabilir, aynı anda birden fazla parametrenin belirlenebildiği düşük maliyetli bir metottur. Çalışma Isparta, Burdur, Antalya, Denizli ve Afyonkarahisar illerinde yapılmıştır. Bu illerdeki yaygın toprak grupları içerisinde horizon tanımlaması yapılmış, örnekler üzerinde yakın kızılötesi yansıma spektroskopisi ile bazı toprak özellikleri arasındaki ilişkilerin belirlenebilirliği ortaya konulmuştur. Ayrıca bu veriler konuyla ilgili oluşacak veri kütüphanesine de katkı sağlayacaktır. Araştırma sonucunda görülebilir yakın kızılötesi yansıma spektroskopisinden alınan değerler ile sırası ile kil $\mathrm{R}^{2}=0.59$, Silt $\mathrm{R}^{2}=0.46$, kum $\mathrm{R}^{2}=0.56$, tarla kapasitesi $\mathrm{R}^{2}=0.74$, solma noktası $\mathrm{R}^{2}=0.67$, kütle yoğunluğu $\mathrm{R}^{2}=0.70, \mathrm{pH}\left(1: 1\right.$, toprak:su) $\mathrm{R}^{2}=0.55, \mathrm{pH}(1: 1$, toprak:KCl) $\mathrm{R}^{2}=0.51$, kireç $\mathrm{R}^{2}=0.90$, organik madde $\mathrm{R}^{2}=0.57$, KDK (katyon değişim kapasitesi) $\mathrm{R}^{2}=0.65$, değişebilir Ca+Mg $\mathrm{R}^{2}=0.64$, değişebilir $\mathrm{K} \mathrm{R}^{2}=0.66$, değişebilir $\mathrm{Na}^{2}=0.58$ ve COLE değeri $\mathrm{R}^{2}=0.50$ olarak belirlenmiştir.
\end{abstract}

Anahtar Kelimeler: Yakın kızılötesi yansıma spektroskopisi (NIRS); Toprak özellikleri; Spektral kütüphane; Spektroradyometre

\section{Determination of Some Soil Properties with Near-infrared Reflectance Spectroscopy}

\section{ARTICLE INFO}

Research Article - Agricultural Technologies

Corresponding Author: Hüseyin ŞENOL, E-mail: huseyinsenol@sdu.edu.tr, Tel: +90(246) 2118607

Received: 24 May 2012, Received in Revised Form: 27 December 2012, Accepted: 10 January 2013 


\begin{abstract}
At the modern soil classification system, it is necessary to determine the soil parameters, which cannot be identified in situ, under the laboratory conditions. The obtained data can be validated and interpreted by soil formation hypotheses. Obtained parameters can be used as a fundamental mechanism to interpret the soil formation processes and the soil classification. There is a wide variety of analysis methods to determine physical and chemical properties of soils. Although time-consuming and expensive methods have been used to determine of these features, some studies on some alternative methods such as NIRS (near-infrared reflectance spectroscopy) have been carried out recently. NIRS method includes some features such as physically harmless analyses of the material, the rapidity, repeatability, allowing simultaneously analyses of more than one parameter and cost-effectiveness. This study reveals the relations between some soil properties and NIRS results of soil samples from horizons of the identified common great groups includes Isparta, Burdur, Antalya, Denizli and Afyonkarahisar provinces in Turkey. On the other hand, these data will provide a contribution to the data library for this area. The following coefficient of determination values $\left(\mathrm{R}^{2}\right)$ between reflectance by NIRS and soil analyses were obtained as follows: clay $\mathrm{R}^{2}=0.59$, silt $\mathrm{R}^{2}=0.59$, sand $\mathrm{R}^{2}=0.56$, field capacity $\mathrm{R}^{2}=0.74$, wilting point $\mathrm{R}^{2}=0.67$, bulk density $\mathrm{R}^{2}=0.70, \mathrm{pH}\left(1: 1\right.$, soil: water) $\mathrm{R}^{2}=0.55, \mathrm{pH}(1: 1$ soil: $\mathrm{KCl}) \mathrm{R}^{2}=0.51$, lime $\mathrm{R}^{2}=0.90$, organic matter $R^{2}=0.57$, CEC (cation exchange capacity) $R^{2}=0.90$, exchangeable $\mathrm{Ca}+\mathrm{Mg} \mathrm{R}^{2}=0.64$, exchangeable $\mathrm{K}$ $\mathrm{R}^{2}=0.66$, exchangeable $\mathrm{Na} \mathrm{R}^{2}=0.58$ and COLE (coefficient of linear extensibility) $\mathrm{R}^{2}=0.50$.
\end{abstract}

Keywords: Near-infrared reflectance spectroscopy (NIRS); Soil properties; Spectral library; Spectroradiometer

(C) Ankara Üniversitesi Ziraat Fakültesi

\section{Giriş}

Hassas tarım tekniklerinin uygulanması, küresel olarak toprakta karbon zenginleşmesinin gözlemlenmesi ve toprak kalitesinin sürdürülebilirliğini sağlayacak toprak özelliklerinin daha hızlı belirlenebileceği, ucuz ve güvenilir yöntemlere olan gereksinim sürekli artmaktadır (Günal et al 2007). Temel doğal öğelerden birisi olan topraklar, toprak nemi, organik madde, mineral bileşim, demir oksitler, tuz ve karbonat içerikleri ile toprak dokusu, toprak yapısı, toprak rengi vb. özellikleri yanında jeolojik yapı ile coğrafi konuma bağımlı olarak ayrımlı yansıma, absorbe, iletme ve dağıtma özellikleri gösterirler. Yakın kızılötesi ışınların bitkilerce yansıtılmalarına karşılık, toprak, kaya vb. diğer öğelerce bu ışınlar değişik oranlarda absorbe edilirler (Altınbaş et al 2001).

Çok sayıda toprak özelliğinin belirlenmesinde hızlı ve ucuz kızılötesi spektroskopi yansımalarının kullanılmasının uygun olduğu düşünülmektedir (Minasy et al 2008, Janik et al 1998, Viscarra Rossel et al 2006, Brown 2007, Brunet et al 2007). Geleneksel toprak analizlerine alternatif olarak düşünülen yansıma spektroskopi çalışmalarında çok az miktarda örnek ile hızlı, ekonomik, örneğe zarar vermeyen, tehlikesiz ve aynı anda birkaç toprak bileşenini bulma imkanı doğmaktadır (Batten 1998). Çok sayıda örneği kısa bir zaman içerisinde analiz ederek, doğruluğu yüksek bilgilere ulaşma olanağı sağladığından spektroskopik analiz teknikleri polimer, eczacılık, petrokimyasal gibi pek çok endüstri alanında tanımlama ve/veya karakterizasyon amaciyla uygulama alanı bulmuştur (Günal et al 2007, McBratney et al 2006, Wetzel 1983, Creaser \& Davies 1988, Murray \& Cowe 1992, Workman 1996).

Spektroskopik yöntemler değişik toprak özelliklerinin hızlı biçimde karakterizasyonu için kullanılmakta ve VIS ile NIR bölgelerindeki 1şıma farklılıklarının bu amaçla kullanımı üzerine araştırmalar yapılmaktadır. Bu çalışmalarda; tahmin edilen pH (Chang et al 2001, Janik et al 1998, Islam et al 2003, Shibusawa et al 2001, Janik \& Skjemstad 1995, Reeves \& McCarty 2001, Shepherd \& Walsh 2002), organik madde (McCarty et al 2002, Chang \& Laird 2002, Reeves et al 1999, Chang et al 2001, Walvoort \& McBratney 2001, Janik \& Skjemstad 1995, Dalal \& Henry 1986, Fidèncio et al 2002, Islam et al 2003, Shepherd \& Walsh 2002, Viscarra Rossel et al 2003, Sørensen \& Dalsgard 2005), hava kurusu nem içeriği (Janik et al 1998, Ben-Dor \& Banin 1995, Dalal \& Henry 1986, Shibusawa et al 2001, 
Chang et al 2001), kil (Janik \& Skjemstad 1995, Ben-Dor \& Banin 1995, Islam et al 2003, Chang et al 2001, Shepherd \& Walsh 2002, Cozzolino \& Moron 2003, Walvoort \& McBratney 2001), kum (Janik et al 1998, Chang et al 2001, Cozzolino \& Moron 2003, Shepherd \& Walsh, 2002, Islam et al 2003), silt (Janik et al 1998, Chang et al 2001, Cozzolino \& Moron 2003, Shepherd \& Walsh, 2002), katyon değişim kapasitesi (CEC) (Janik et al 1998, Ben-Dor \& Banin 1995, Islam et al 2003, Chang et al 2001, Shepherd \& Walsh 2002, Islam et al 2005), kil mineralleri (Dematte et al 2004, Brown et al 2006), değiş̧ebilir Ca (Shepherd \& Walsh 2002, Chang et al 2001) ve değiş̧ebilir Mg (Chang et al 2001, Shepherd \& Walsh 2002, Islam et al 2003, 2005) gibi toprak özeliklerinin belirlenmesinde ve bu özelliklerin 1şımaya olan doğrudan etkilerinden dolayı kullanılabileceği gösterilmeye çalışılmıştır. $\mathrm{Bu}$ çalışmada farklı ana materyaller üzerinde oluşmuş toprakların yakın kızılötesi yansıma spektroskopisi ile bazı toprak özellikleri arasındaki ilişkilerin belirlenmesi amaçlanmıştır. Toprak oluşumunda meydana gelen kantitatif değişimler spektroskopik yöntemlerle ortaya konulmuştur.

\section{Materyal ve Yöntem}

\section{1. Çalışma alanı}

Isparta, Burdur, Antalya, Denizli ve Afyonkarahisar illerinin yaygın toprak grupları içerisinde seçilen 16 adet toprak profili içerisinde çalışılmıştır. Toplam 68 adet toprak örneği kullanılmıştır. Çalışma alanı ve açılan toprak profilleri Şekil 1'de pozisyon, ana materyal ve anakaya özellikleri ise Çizelge 1'de gösterilmektedir.

\subsection{Fiziksel ve kimyasal analizler}

Toprak örnekleri plastik kaplarda laboratuvara getirilmiş, havada kurutulmuş ve 2 mm'lik elekten geçirilerek plastik kaplarda saklanmıştır (Anonymous 1951). Tane büyüklük dağılımı hidrometre yöntemi ile (Bouyoucos 1951), bozulmuş toprak örnekleri kullanılarak tarla kapasitesi $33 \mathrm{kPa}$ ve solma noktası $1500 \mathrm{kPa}$ basınç altında basınçlı plaka aleti kullanılarak saptanmıştır (Demiralay 1993).
Kütle yoğunluğu $100 \mathrm{~cm}^{39}$ lük metal silindirler içine alınan örneklerin $105{ }^{\circ} \mathrm{C}$ 'de kurutularak silindir hacmine bölünmesiyle (Blake \& Hartge 1986), $\mathrm{pH}$ değerleri 1:1'lik toprak-su ve 1:1'lik $1 \mathrm{~N} \mathrm{KCl}$ karışımlarında cam elektrodlu $\mathrm{pH}$ metre kullanılarak (Jackson 1958), kireç içerikleri $\mathrm{CaCO}_{3}$ eşdeğerleri olarak Scheibler kalsimetresi ile volumetrik yöntem kullanılarak belirlenmiştir (Hızalan \& Ünal 1966). Organik madde tespiti değiştirilmiş Walkley-Black yöntemine göre yapılmıştır (Jackson 1958). Katyon değişim kapasitesi değerleri, toprakların Na-asetat ile doyurulmasindan sonra amonyum asetat ile ekstrakte edilmesi ve ekstrakte edilen sodyumun atomik absorbsiyon spektrofotometresinde okunmasiyla ortaya konulmuştur (Anonymous 1973). Katyonlar

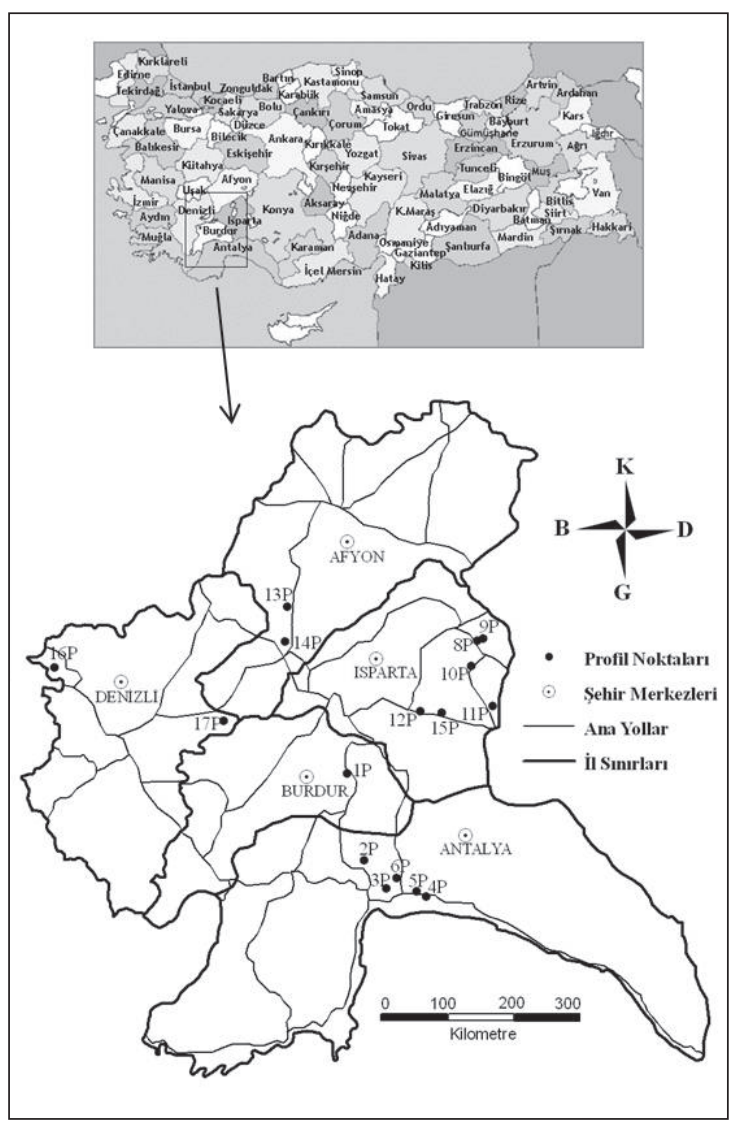

Şekil 1- Çalışma alanı içerisindeki toprak profil noktaları

Figure 1- The study area within the soil profile points 
amonyum asetat ile ekstrakte edildikten sonra, $\mathrm{Mg}^{++}, \mathrm{Ca}^{++}, \mathrm{Na}^{+}$ve $\mathrm{K}^{+}$atomik absorbsiyon cihazında belirlenmiş, bir kısım örnekler doğrudan bu şekilde belirlenirken bir kısım örnekler $\mathrm{Mg}^{++}+\mathrm{Ca}^{++}$değerleri katyon değişim kapasitesinden yüksek çıktığından, değişebilir $\mathrm{Mg}^{++}+\mathrm{Ca}^{++}$miktarlarının katyon değişim kapasitesinden $\mathrm{Na}^{+}$ve $\mathrm{K}^{+}$katyonlarının çıkarılmasıyla elde edilmiştir (Anonymous 1954). COLE değeri (doğrusal genişleyebilirlik katsayısı) hesaplanırken, doygunluktan biraz daha düşük nem düzeyinde balçıklaştırılan topraktan bir şırınga yardımıyla $1 \mathrm{~cm}$ çapında ve 6-10 cm uzunluğunda çubuklar alınmış, bu çubuklar 48 saat atmosfer koşullarında kurutulmuş ve sonrasında ölçülen uzunluk değerlerine göre aşağıdaki formül kullanılmıştır (Schafer \& Singer 1976).

$$
\text { COLE }=\frac{L_{m}-L_{d}}{L_{d}}
$$

COLE: Doğrusal genişleyebilirlik katsayısı; $\mathrm{L}_{\mathrm{m}}$ : Nemli çubuğun uzunluğu $(\mathrm{cm}) ; \mathrm{L}_{\mathrm{d}}$ : Kuru çubuğun uzunluğudur $(\mathrm{cm})$.

\subsection{Yakın kızılötesi yansıma spektroskopisi ile yansımaların alımı ve istatistik analizi}

ToprakörnekleriAdnan Menderes Üniversitesi Ziraat Fakültesi Toprak Bilimi ve Bitki Besleme Bölümü laboratuvarlarında ASD FieldSpec Pro FR VNIR cihazı (ASD Inc., USA) kullanılarak 350-2500 nm dalga boylarından $1 \mathrm{~nm}$ çözünürlükte kontak prob vasıtası ile taranmıştır. Kendi ışık kaynağını içeren kontak prob, $2 \mathrm{~cm}$ çapında bir görüntüleme alanına sahiptir. Her bir örneğin taraması yapılmadan önce beyaz referans paneli (polytetraflouroethylene (PTFE) ve cinteredhalon, ASD Inc., USA) \% 99 yansıtma özelliği ile spektrometrenin optimize edilmesi için kullanılmıştır. Örnek taramaları sırasında optimizasyon işlemi 15 dakika aralıklar ile tekrarlanmıştır. Taramalar yaklaşık $20 \mathrm{~g}$ toprak örneği içeren borosilikat cam petri kabında okunmuş, her bir örnek üç paralelli olarak $90^{\circ}$ açıyla taranmış ve ortalamaları alınmıştır.

\section{Bulgular ve Tartışma}

Çalışma toplam 68 adet toprak örneği üzerinde yürütülmüş ve çalışılan parametrelere ait kalibrasyon ve validasyon RMSE değerleri ile belirtme katsayıları Çizelge 2'de, örneklere ait gerçek ve tahmin edilen değerler Çizelge 3 ve 4'de verilmiştir.

\section{Çizelge 1- Çalışma alanı profillerin pozisyon, ana materyal ve ana kaya özellikleri}

Table 1-Study area in profiles, position, parent material and rock properties

\begin{tabular}{|c|c|c|c|c|}
\hline Horizon & Örnek sayısı & Pozisyon & Ana materyal & Ana kaya \\
\hline $1 \mathrm{P}$ & 4 & Taban arazi & Kireçli alüviyal & Akdağ kireçtaşları (Gutnic et al 1979) \\
\hline $2 \mathrm{P}$ & 4 & Kolüviyal etek & Kolüflüviyal çamur akıntısı & Kızılkırma formasyonu (Karaman et al 1988) \\
\hline $3 \mathrm{P}$ & 5 & Deniz terası & Traverten & Traverten (Koşun et al 2005) \\
\hline $4 \mathrm{P}$ & 3 & Alt etek & Çertli kolüviyal & Çert (Koşun et al 2005) \\
\hline $5 \mathrm{P}$ & 4 & Taban arazi & Kireçli alüviyal & Alüviyal kireçtaşı (Koşun et al 2005) \\
\hline $6 \mathrm{P}$ & 4 & Deniz terası & Kolüviyal çamur akıntısı & Traverten (Koşun et al 2005) \\
\hline $8 \mathrm{P}$ & 4 & Alt etek & Kireçli kolüviyal & Aktaşsırtı kireçtaşları (Öncel 1995) \\
\hline $9 \mathrm{P}$ & 4 & Etek & Kireçli kolüviyal & Bağkonak formasyonu (Demirkol 1984) \\
\hline $10 \mathrm{P}$ & 4 & Etek & Kireçli kolüviyal & \multirow{2}{*}{ Anamas kireçtaşları (Gutnic et al 1979) } \\
\hline $11 \mathrm{P}$ & 4 & Alt etek & Kolüviyal çamur akıntısı & \\
\hline $12 \mathrm{P}$ & 5 & Yamaç & Çertli kolüviyal & Yilanlı formasyonu (Waldron 1984) \\
\hline $13 \mathrm{P}$ & 6 & Taban arazi & Kireçli alüviyal & Türkbelkavak formasyonu (Koçyiğit et al 2001) \\
\hline $14 \mathrm{P}$ & 4 & Alt etek & Kumtaşı alüviyal & Kızılören formasyonu (Koçyiğit et al 2001) \\
\hline $15 \mathrm{P}$ & 4 & Alt etek & Çertli kolüviyal & Kasımlar formasyonu (Şahin 1997) \\
\hline $16 \mathrm{P}$ & 4 & Sirt & Gnays kolüviyal & Çine formasyonu (Schulling 1973) \\
\hline $17 \mathrm{P}$ & 5 & Göl tabanı & Kireçli ve jipsli taban & Eski gölsel tortullar (Alcicek 2009) \\
\hline
\end{tabular}


Çizelge 2- Çalışılan toprak özelliklerine ait RMSE ve belirtme katsayıları

Table 2-RMSE and the determination of the coefficients of the studied soil properties

\begin{tabular}{|c|c|c|c|c|}
\hline \multirow{2}{*}{ Parametre } & \multicolumn{2}{|c|}{$R M S E$} & \multirow{2}{*}{$R^{2}$ (Kal.) } & \multirow{2}{*}{$R^{2}$ (Val.) } \\
\hline & Kalibrasyon & Validasyon & & \\
\hline Kil & 7.631 & 11.844 & 0.67 & 0.59 \\
\hline Silt & 5.760 & 8.619 & 0.59 & 0.46 \\
\hline Kum & 8.101 & 15.058 & 0.68 & 0.56 \\
\hline Tarla Kapasitesi & 3.557 & 7.396 & 0.88 & 0.74 \\
\hline Solma Noktas1 & 3.067 & 5.658 & 0.73 & 0.67 \\
\hline Kütle Yoğunluğu & 0.086 & 0.213 & 0.75 & 0.70 \\
\hline $\mathrm{pH}(\mathrm{su})$ & 0.593 & 0.669 & 0.58 & 0.55 \\
\hline $\mathrm{pH}(\mathrm{KCl})$ & 0.599 & 0.989 & 0.53 & 0.51 \\
\hline Kireç (CaCO3) & 9.633 & 14.299 & 0.94 & 0.90 \\
\hline Organik Madde & 0.406 & 0.696 & 0.59 & 0.57 \\
\hline KDK & 5.595 & 10.290 & 0.75 & 0.65 \\
\hline Değișebilir $\mathrm{Ca}+\mathrm{Mg}$ & 5.617 & 10.181 & 0.73 & 0.64 \\
\hline Değişebilir $\mathrm{Na}$ & 0.243 & 0.420 & 0.62 & 0.58 \\
\hline Değişebilir K & 0.236 & 0.465 & 0.69 & 0.66 \\
\hline COLE & 0.024 & 0.039 & 0.55 & 0.50 \\
\hline
\end{tabular}

Çizelge 3- Çalışılan toprakların gerçek ve tahmin edilen değerleri

Table 3-Measured and predicted values of the studied soils

\begin{tabular}{|c|c|c|c|c|c|c|c|c|c|c|c|c|c|c|c|c|}
\hline \multirow{2}{*}{$\begin{array}{c}\text { Örnek } \\
\text { No }\end{array}$} & \multicolumn{2}{|c|}{ Kil } & \multicolumn{2}{|c|}{ Silt } & \multicolumn{2}{|c|}{ Kum } & \multicolumn{2}{|c|}{$T K$} & \multicolumn{2}{|c|}{$S N$} & \multicolumn{2}{|c|}{ K. Yŏg. } & \multicolumn{2}{|c|}{$p H, s u$} & \multicolumn{2}{|c|}{$p H, K C l$} \\
\hline & $M$ & $P$ & $M$ & $P$ & $M$ & $P$ & $M$ & $P$ & $M$ & $P$ & $M$ & $P$ & $M$ & $P$ & $M$ & $P$ \\
\hline $1 \mathrm{P} 1$ & 44.31 & 38.83 & 24.00 & 26.27 & 31.69 & 38.64 & 28.79 & 27.93 & 21.67 & 17.85 & 1.57 & 1.57 & 7.66 & 7.56 & 6.82 & 6.84 \\
\hline 1P2 & 37.89 & 37.21 & 33.28 & 28.13 & 28.83 & 38.13 & 26.76 & 27.83 & 15.49 & 15.61 & 1.63 & 1.63 & 7.68 & 7.80 & 6.87 & 7.12 \\
\hline $1 \mathrm{P} 3$ & 27.99 & 40.68 & 36.48 & 29.93 & 35.53 & 30.03 & 24.62 & 31.59 & 12.97 & 17.40 & 1.59 & 1.59 & 7.69 & 7.71 & 6.84 & 6.89 \\
\hline $1 \mathrm{P} 4$ & 21.03 & 34.24 & 14.36 & 26.63 & 64.61 & 44.98 & 18.51 & 26.93 & 11.33 & 16.67 & 1.90 & 1.90 & 7.65 & 8.38 & 6.86 & 7.54 \\
\hline $2 \mathrm{P} 1$ & 43.66 & 44.58 & 39.10 & 30.38 & 17.23 & 23.43 & 32.55 & 29.17 & 24.31 & 20.28 & 1.28 & 1.28 & 7.26 & 7.42 & 6.60 & 6.81 \\
\hline $2 \mathrm{P} 2$ & 49.73 & 46.84 & 30.38 & 29.43 & 19.89 & 21.53 & 33.53 & 32.66 & 25.19 & 21.00 & 1.30 & 1.30 & 6.97 & 7.33 & 6.14 & 6.67 \\
\hline $2 \mathrm{P} 3$ & 48.15 & 43.36 & 35.96 & 30.63 & 15.89 & 24.87 & 33.84 & 29.63 & 24.37 & 20.01 & 1.46 & 1.46 & 7.09 & 7.54 & 6.20 & 6.85 \\
\hline $2 \mathrm{P} 4$ & 43.15 & 42.48 & 42.50 & 31.46 & 14.35 & 24.88 & 31.89 & 34.02 & 22.00 & 21.70 & 1.57 & 1.57 & 7.77 & 7.25 & 6.79 & 6.40 \\
\hline $3 \mathrm{P} 1$ & 46.50 & 45.70 & 21.38 & 25.87 & 32.13 & 28.92 & 22.48 & 23.30 & 15.16 & 16.13 & 1.47 & 1.47 & 7.66 & 7.17 & 7.18 & 6.46 \\
\hline $3 \mathrm{P} 2$ & 47.41 & 53.12 & 20.44 & 18.94 & 32.15 & 28.75 & 23.82 & 24.49 & 16.23 & 18.01 & 1.42 & 1.42 & 7.76 & 7.17 & 7.15 & 6.64 \\
\hline $3 \mathrm{P} 3$ & 54.56 & 65.04 & 19.23 & 17.34 & 26.20 & 13.30 & 26.34 & 27.67 & 17.89 & 22.40 & 1.48 & 1.48 & 7.74 & 6.41 & 7.10 & 5.84 \\
\hline $3 \mathrm{P} 4$ & 60.24 & 56.24 & 22.11 & 18.68 & 17.65 & 24.45 & 28.73 & 24.40 & 20.94 & 21.01 & 1.52 & 1.52 & 7.70 & 6.25 & 7.01 & 5.73 \\
\hline $3 \mathrm{P} 5$ & 61.18 & 64.95 & 22.22 & 14.82 & 16.60 & 17.46 & 29.51 & 28.32 & 19.98 & 21.88 & 1.53 & 1.53 & 7.67 & 6.28 & 6.95 & 5.73 \\
\hline $4 \mathrm{P} 1$ & 33.20 & 42.51 & 12.63 & 22.54 & 54.17 & 39.02 & 17.98 & 19.04 & 13.90 & 15.32 & 1.20 & 1.20 & 5.33 & 6.02 & 5.39 & 5.87 \\
\hline $4 \mathrm{P} 2$ & 49.84 & 53.47 & 11.65 & 9.83 & 38.51 & 42.71 & 28.29 & 21.56 & 20.65 & 19.50 & 1.31 & 1.31 & 5.88 & 5.06 & 5.75 & 4.69 \\
\hline $4 \mathrm{P} 3$ & 46.71 & 58.58 & 9.03 & 9.57 & 44.27 & 35.42 & 26.88 & 25.23 & 16.80 & 21.48 & 1.05 & 1.05 & 4.99 & 4.79 & 5.12 & 4.54 \\
\hline $5 \mathrm{P} 1$ & 26.61 & 22.00 & 53.01 & 46.39 & 20.38 & 32.02 & 27.75 & 25.93 & 10.24 & 7.37 & 1.42 & 1.42 & 7.66 & 7.59 & 7.34 & 7.02 \\
\hline $5 \mathrm{P} 2$ & 21.38 & 18.85 & 48.19 & 46.39 & 30.42 & 36.77 & 23.10 & 21.95 & 8.88 & 5.99 & 1.47 & 1.47 & 7.78 & 7.85 & 7.31 & 7.27 \\
\hline $5 \mathrm{P} 3$ & 30.32 & 25.02 & 55.79 & 49.70 & 13.90 & 22.21 & 28.12 & 30.15 & 11.00 & 10.04 & 1.52 & 1.52 & 7.78 & 8.31 & 7.25 & 7.74 \\
\hline $5 \mathrm{P} 4$ & 41.48 & 28.10 & 48.44 & 42.41 & 10.08 & 29.15 & 31.40 & 30.72 & 16.28 & 12.67 & 1.46 & 1.46 & 7.83 & 8.09 & 7.13 & 7.52 \\
\hline $6 \mathrm{P} 1$ & 56.94 & 55.87 & 24.93 & 24.86 & 18.14 & 15.19 & 30.12 & 30.31 & 20.90 & 21.49 & 1.13 & 1.13 & 7.13 & 6.53 & 6.65 & 6.10 \\
\hline $6 \mathrm{P} 2$ & 67.20 & 77.73 & 24.53 & 15.99 & 8.27 & 3.68 & 33.74 & 36.35 & 22.62 & 28.73 & 1.42 & 1.42 & 7.46 & 6.75 & 6.87 & 6.03 \\
\hline $6 \mathrm{P} 3$ & 71.55 & 77.19 & 21.36 & 16.91 & 7.10 & 4.34 & 38.69 & 40.95 & 27.54 & 31.00 & 1.45 & 1.45 & 7.21 & 7.20 & 6.44 & 6.71 \\
\hline
\end{tabular}


Çizelge 3- (Devam) Çalışılan toprakların gerçek ve tahmin edilen değerleri

Table 3-Measured and predicted values of the studied soils (continuation of the table 3)

\begin{tabular}{|c|c|c|c|c|c|c|c|c|c|c|c|c|c|c|c|c|}
\hline \multirow{2}{*}{$\begin{array}{c}\text { Örnek } \\
N o\end{array}$} & \multicolumn{2}{|c|}{ Kil } & \multicolumn{2}{|c|}{ Silt } & \multicolumn{2}{|c|}{ Kum } & \multicolumn{2}{|c|}{$T K$} & \multicolumn{2}{|c|}{$S N$} & \multicolumn{2}{|c|}{ K. Yoğ. } & \multicolumn{2}{|c|}{$p H, s u$} & \multicolumn{2}{|c|}{$\mathrm{pH}, \mathrm{KCl}$} \\
\hline & $M$ & $P$ & $M$ & $P$ & $M$ & $P$ & $M$ & $P$ & $M$ & $P$ & $M$ & $P$ & $M$ & $P$ & $M$ & $P$ \\
\hline $6 \mathrm{P} 4$ & 77.42 & 73.70 & 16.13 & 11.78 & 6.45 & 9.10 & 41.56 & 38.14 & 30.84 & 30.58 & 1.39 & 1.39 & 6.80 & 6.24 & 6.14 & 5.67 \\
\hline 8P1 & 49.16 & 9.53 & 28.85 & 27.03 & 21.99 & 21.28 & 29.10 & & 16.91 & 19.80 & 1.16 & & 7.63 & 7.27 & 7.02 & 6.46 \\
\hline $8 \mathrm{P} 2$ & 51.48 & 52.12 & 25.74 & 24.53 & 22.79 & 21.36 & 29.99 & 35.07 & 22.05 & 24.99 & 1.15 & 1. & 7.68 & 7.59 & 7.01 & 6.88 \\
\hline 8P3 & 8.65 & 45.04 & 26.73 & 29.08 & 24.62 & 24.81 & 31.07 & 30.73 & 21.10 & 19.30 & 1.21 & 1.2 & 7.69 & 7.76 & 7.01 & 7.01 \\
\hline $8 \mathrm{P} 4$ & 43.41 & 46.26 & 24.35 & 20.76 & 32.24 & 36.19 & 26.05 & 26.83 & 17.28 & 20.18 & 1.24 & 1.2 & 7.69 & 7.66 & 7.01 & 7.18 \\
\hline 9P1 & 52.68 & 46.76 & 26.07 & 25.74 & 21.25 & 27.52 & 29.94 & 29.18 & 19.10 & 18.42 & 1.22 & 1.22 & 7.55 & 7.46 & 7.05 & 6.85 \\
\hline 9P2 & 54.75 & 49.88 & 26.58 & 27.30 & 18.68 & 20.34 & 29.60 & 27.67 & 19.29 & 18.68 & 1.45 & 1.45 & 7.53 & 7.22 & 7.02 & 6.53 \\
\hline 9P3 & 57.13 & 46.09 & 25.63 & 25.60 & 17.25 & 28.76 & 30.55 & 27.85 & 21.35 & 18.33 & 1.41 & 1.41 & 7.62 & 7.30 & 6.99 & 6.55 \\
\hline 9P4 & 54.84 & 55.59 & 27.69 & 20.08 & 17.47 & 23.20 & 29.09 & 28.65 & 20.52 & 21.91 & 1.60 & 1.60 & 7.68 & 6.98 & 6.93 & 6.37 \\
\hline 10P1 & 33.70 & 38.52 & 16.32 & 21.04 & 49.98 & 47.41 & 24.17 & 27.05 & 17.25 & 18.77 & - & - & 7.29 & & 6.90 & 6.61 \\
\hline 10P2 & 34.65 & 37.81 & 14.70 & 21.09 & 50.65 & 48.42 & 24.75 & 25.88 & 19.28 & 19.24 & - & - & 7.31 & 7.65 & 6.96 & 7.37 \\
\hline 10P3 & 34.72 & 40.07 & 11.29 & 20.39 & 53.98 & 46.12 & 23.23 & 21.83 & 18.15 & 17.14 & - & - & 7.55 & & 6.97 & 6.32 \\
\hline $10 \mathrm{P} 4$ & 30.85 & 32.80 & 11.42 & 24.26 & 57.74 & 50.93 & 19.84 & 19. & 16.42 & 14.08 & - & - & 7.65 & 7. & 7.01 & 6.87 \\
\hline 11P1 & 59.92 & 57.28 & 24.23 & 23.97 & 15.85 & 14.47 & 23.51 & 29.89 & 16.63 & 19.45 & 1.50 & 1. & 6.21 & & 5.93 & 6.36 \\
\hline $11 \mathrm{P} 2$ & 60.52 & 53.27 & 26.44 & 21.40 & 13.04 & 24.60 & 26.66 & 20. & 18.38 & 16.28 & 1.4 & 1. & 6.86 & & 6.4 & 5.96 \\
\hline $11 \mathrm{P} 3$ & 65.76 & 62.14 & 22.16 & 22.81 & 12.08 & 8.99 & 28.51 & 31.97 & 19.24 & 23.00 & 1.54 & 1. & 6.77 & 6. & 6.47 & 6.43 \\
\hline $11 \mathrm{P} 4$ & 6.47 & 57.39 & 21.83 & 23.17 & 11.70 & 56 & 27.77 & 28. & 20.07 & 20. & 1.5 & & 6.8 & & 6.2 & 6.10 \\
\hline 12P1 & 60.30 & 54.16 & 18.34 & 20.28 & 21.37 & 25.05 & 26.45 & 22.74 & 17.97 & 17.80 & 1.29 & 1.2 & 4.56 & 5. & 3.98 & 4.66 \\
\hline $12 \mathrm{P} 2$ & .26 & 56.12 & 20.65 & 16.2 & 23.09 & 28. & 26.71 & 23. & 19. & 19. & 1.3 & & 4.58 & & 3. & 4.35 \\
\hline $12 \mathrm{P} 3$ & 57.00 & 54.18 & 17.98 & 15.95 & 25.03 & 31.90 & 26.26 & 20.52 & 18.35 & 16.29 & 1.46 & 1.4 & 4.55 & & 3.6 & 4.94 \\
\hline $12 \mathrm{P} 4$ & .31 & 51.90 & 20.31 & 23.9 & 30.39 & 22.65 & 23.59 & 23. & 17.07 & 17. & - & - & 4.44 & & 3.6 & 4.84 \\
\hline $12 \mathrm{P} 5$ & 34.92 & 36.88 & 24.57 & 25.87 & 40.52 & 42.22 & 17.92 & 19.72 & 10.49 & 11.34 & - & - & 4.19 & 5. & 3.81 & 5.26 \\
\hline 13P1 & .46 & 53.78 & 22.34 & 28.94 & 23.20 & & 35.07 & 39.9 & 24.41 & 26.38 & 1.2 & & 7.62 & & 6.9 & 7.09 \\
\hline 13P2 & 52.85 & 43.64 & 23.45 & 24.22 & 23.70 & 34.66 & 35.47 & 34.26 & 25.65 & 22.13 & 1.18 & 1. & 7.76 & & 6.9 & 6.94 \\
\hline $13 \mathrm{P} 3$ & .56 & 49.47 & 27.65 & 25.75 & 18.79 & 23.41 & 39.77 & 36.5 & 27.59 & 25.02 & 1.13 & 1.1 & 7.69 & & 6.9 & 7.17 \\
\hline 13P4 & 51.45 & 48.33 & 31.57 & 33.91 & 16.98 & 12.16 & 44.01 & 42.85 & 28.13 & 23.99 & - & - & 7.72 & & 6.7 & 7.04 \\
\hline 13P5 & 51.34 & 45.37 & 30.57 & 26.18 & 18.09 & 28.93 & 40.35 & 34.05 & 26.39 & 21.74 & - & - & 7.74 & & 6.95 & 6.72 \\
\hline 13P6 & 45.70 & 45.91 & 38.81 & 33.37 & 15.49 & 16.65 & 46.08 & 40.79 & 28.34 & 24.10 & 1.21 & & 7.77 & & 6.7 & 7.42 \\
\hline 14P1 & 30.65 & 36.01 & 15.27 & 25.70 & 54.08 & 43.79 & 18.20 & 23.94 & 9.54 & 13.07 & 1.51 & 1.5 & 6.48 & 7.5 & 6.65 & 7.40 \\
\hline $14 \mathrm{P} 2$ & 28.07 & 42.01 & 28.87 & 26.78 & 43.06 & & 17. & 19. & 11.33 & & 1.69 & & 6.96 & & 6.3 & 5.81 \\
\hline 14P3 & 41.49 & 50.99 & 18.74 & 19.81 & 39.77 & 30.58 & 24.64 & 26.98 & 15.71 & 19.06 & 1.69 & 1.6 & 7.05 & 6.93 & 6.56 & 6.33 \\
\hline $14 \mathrm{P} 4$ & 63.16 & 64.43 & 13.67 & 16.16 & 23.17 & & 40.20 & 37. & 28.09 & & 1.44 & & 6.73 & & 6. & 6.33 \\
\hline $15 \mathrm{P} 1$ & 39.11 & 39.27 & 36.26 & 29.08 & 24.63 & 33.51 & 22.16 & 24.60 & 13.21 & 15.25 & 1.50 & 1.5 & 6.95 & 7.29 & 6.50 & 6.82 \\
\hline $15 \mathrm{P} 2$ & 47.97 & 44.46 & 31.27 & 26.55 & 20.76 & & 27.86 & 26.22 & 18.29 & & 1.63 & & 7.68 & & 6. & 5.97 \\
\hline $15 \mathrm{P} 3$ & 40.53 & 49.30 & 31.39 & 28.90 & 28.08 & 18.66 & 26.10 & 29.96 & 17.92 & 19.29 & 1.71 & 1.71 & 7.55 & 7.28 & 6.98 & 6.61 \\
\hline $15 \mathrm{P} 4$ & 38.29 & 40.70 & 32.32 & 24.44 & 29.39 & & 23.55 & 18. & 16.64 & 14.52 & - & - & 7.49 & & 7.0 & 6.47 \\
\hline 16P1 & 14.86 & 23.34 & 26.88 & 34.62 & 58.26 & 48.73 & 19.40 & 21.65 & 5.64 & 8.07 & 1.19 & 1.1 & 5.99 & 6.87 & 5.69 & 6.50 \\
\hline $16 \mathrm{P} 2$ & 18.40 & 31.21 & 31.41 & 30.13 & 50.20 & 44.01 & 18.30 & 19.50 & 6.05 & 8.36 & 1.50 & 1.50 & 5.80 & & 5.24 & 5.73 \\
\hline $16 \mathrm{P} 3$ & 18.51 & 33.28 & 26.48 & 29.02 & 55.01 & 42.64 & 15.62 & 20.20 & 6.79 & 9.78 & - & - & 5.15 & 5.93 & 3.76 & 4.64 \\
\hline $16 \mathrm{P} 4$ & 19.14 & 31.66 & 28.20 & 30.70 & 52.65 & 42.39 & 15.67 & 18.05 & 6.25 & 9.51 & - & - & 4.73 & 5. & 3.66 & 4.78 \\
\hline 17P1 & 61.83 & 48.19 & 25.68 & 33.12 & 12.48 & 13.61 & 42.60 & 40.68 & 29.91 & 23.76 & 1.18 & 1.18 & 8.34 & 8.29 & 7.26 & 7.33 \\
\hline 17P2 & 57.81 & 47.93 & 23.82 & 31.37 & 18.37 & 16.80 & 41.26 & 42.15 & 23.50 & 22.66 & 1.14 & 1.1 & 8.55 & 8.69 & 7.48 & 7.73 \\
\hline 17P3 & 57.02 & 43.84 & 24.54 & 30.99 & 18.44 & 23.58 & 35.85 & 35.63 & 22.17 & 18.52 & 1.47 & 1.47 & 8.57 & 8.16 & 7.57 & 7.30 \\
\hline 17P4 & 57.15 & 49.25 & 24.89 & 31.28 & 17.96 & 14.96 & 37.79 & 44.93 & 22.20 & 24.41 & 1.39 & 1. & 8.00 & 8.39 & 7.69 & 7.71 \\
\hline 17P5 & 66.61 & 42.39 & 13.62 & 30.39 & 19.77 & 26.72 & 55.16 & 45.03 & 31.42 & 21.54 & 1.16 & 1.16 & 7.93 & 8.20 & 7.41 & 7.62 \\
\hline
\end{tabular}

M: Ölçülen değer, P: Tahmin edilen değer 
Çizelge 4- Çalışılan toprakların gerçek ve tahmin edilen değerleri

Table 4-Measured and predicted values of the studied soils

\begin{tabular}{|c|c|c|c|c|c|c|c|c|c|c|c|c|c|c|}
\hline \multirow{2}{*}{$\begin{array}{c}\text { Örnek } \\
\text { No }\end{array}$} & \multicolumn{2}{|c|}{$\mathrm{CaCO}_{3}$} & \multicolumn{2}{|c|}{ Org. M. } & \multicolumn{2}{|c|}{$K D K$} & \multicolumn{2}{|c|}{ De ğ. $C a+M g$} & \multicolumn{2}{|c|}{ Değ. $N a$} & \multicolumn{2}{|c|}{ Değ. $K$} & \multicolumn{2}{|c|}{ COLE } \\
\hline & $M$ & $P$ & $M$ & $P$ & $M$ & $P$ & $M$ & $P$ & $M$ & $P$ & $M$ & $P$ & $M$ & $P$ \\
\hline 1P1 & 10.67 & 18.76 & 0.83 & 0.87 & 45.19 & 37.27 & 44.23 & 36.34 & 0.17 & 0.29 & 0.80 & 0.57 & 0.17 & 0.12 \\
\hline $1 \mathrm{P} 2$ & 37.01 & 25.05 & 0.35 & 0.63 & 37.34 & 34.66 & 36.72 & 33.73 & 0.16 & 0.34 & 0.46 & 0.57 & 0.10 & 0.08 \\
\hline 1P3 & 21.03 & 22.37 & 0.16 & 0.61 & 37.39 & 34.05 & 36.98 & 32.91 & 0.04 & 0.44 & 0.37 & 0.71 & 0.07 & 0.08 \\
\hline $1 \mathrm{P} 4$ & 5.36 & 5.53 & 0.08 & 0.72 & 29.42 & 40.87 & 28.90 & 40.01 & 0.15 & 0.34 & 0.36 & 0.33 & 0.03 & 0.09 \\
\hline $2 \mathrm{P} 1$ & 1.37 & 0.80 & 3.99 & 2.49 & 50.54 & 42.53 & 49.26 & 41.15 & 0.33 & 0.30 & 0.94 & 0.97 & 0.14 & 0.11 \\
\hline $2 \mathrm{P} 2$ & 1.09 & 1.37 & 1.95 & 1.81 & 46.52 & 39.94 & 45.31 & 38.41 & 0.42 & 0.49 & 0.80 & 0.98 & 0.17 & 0.12 \\
\hline $2 \mathrm{P} 3$ & 0.57 & 0.42 & 1.11 & 1.54 & 52.61 & 42.40 & 51.67 & 41.10 & 0.35 & 0.46 & 0.60 & 0.69 & 0.14 & 0.11 \\
\hline $2 \mathrm{P} 4$ & 5.98 & 5.92 & 0.78 & 0.94 & 49.48 & 44.12 & 48.61 & 42.92 & 0.34 & 0.37 & 0.54 & 0.63 & 0.15 & 0.13 \\
\hline $3 \mathrm{P} 1$ & 27.46 & 23.02 & 1.92 & 1.14 & 36.05 & 39.20 & 35.23 & 38.39 & 0.13 & 0.16 & 0.70 & 0.56 & 0.08 & 0.09 \\
\hline $3 \mathrm{P} 2$ & 30.80 & 29.99 & 1.24 & 0.77 & 31.07 & 33.71 & 30.45 & 33.41 & 0.08 & 0.26 & 0.53 & 0.60 & 0.09 & 0.11 \\
\hline $3 \mathrm{P} 3$ & 20.72 & 20.03 & 0.79 & 0.67 & 29.20 & 34.42 & 28.66 & 33.94 & 0.06 & 0.15 & 0.48 & 0.66 & 0.13 & 0.14 \\
\hline $3 \mathrm{P} 4$ & 13.52 & 15.91 & 0.54 & 0.57 & 32.44 & 39.15 & 31.93 & 38.87 & 0.03 & 0.16 & 0.47 & 0.32 & 0.13 & 0.14 \\
\hline $3 \mathrm{P} 5$ & 11.69 & 10.43 & 0.53 & 0.34 & 34.84 & 35.83 & 34.30 & 35.50 & 0.04 & 0.24 & 0.50 & 0.56 & 0.04 & 0.10 \\
\hline $4 \mathrm{P} 1$ & 0.53 & 0.12 & 2.15 & 1.84 & 26.37 & 32.88 & 25.68 & 32.19 & 0.17 & 0.12 & 0.52 & 0.90 & 0.06 & 0.09 \\
\hline $4 \mathrm{P} 2$ & 0.64 & 0.47 & 0.87 & 0.21 & 30.72 & 30.23 & 30.21 & 30.59 & 0.02 & 0.30 & 0.49 & 0.63 & 0.13 & 0.13 \\
\hline $4 \mathrm{P} 3$ & 0.49 & 0.40 & 0.19 & 0.21 & 37.79 & 44.36 & 37.36 & 44.05 & 0.03 & 0.18 & 0.40 & 0.26 & 0.13 & 0.16 \\
\hline $5 \mathrm{P} 1$ & 34.20 & 34.57 & 1.73 & 1.58 & 24.89 & 15.49 & 23.85 & 14.74 & 0.21 & 0.50 & 0.83 & 0.59 & 0.04 & 0.02 \\
\hline $5 \mathrm{P} 2$ & 35.31 & 33.52 & 0.83 & 1.42 & 21.00 & 17.33 & 20.55 & 16.97 & 0.07 & 0.32 & 0.39 & 0.31 & 0.04 & 0.03 \\
\hline $5 \mathrm{P} 3$ & 33.89 & 35.75 & 1.08 & 1.89 & 27.07 & 23.70 & 26.32 & 22.47 & 0.16 & 0.59 & 0.59 & 0.87 & 0.06 & 0.04 \\
\hline $5 \mathrm{P} 4$ & 33.99 & 32.35 & 1.28 & 2.11 & 32.18 & 27.24 & 31.54 & 26.10 & 0.07 & 0.39 & 0.57 & 0.92 & 0.10 & 0.06 \\
\hline $6 \mathrm{P} 1$ & 0.36 & 0.25 & 1.37 & 1.10 & 42.66 & 38.91 & 41.82 & 38.09 & 0.09 & 0.17 & 0.74 & 0.54 & 0.13 & 0.12 \\
\hline $6 \mathrm{P} 2$ & 0.58 & 0.55 & 0.76 & 0.91 & 39.84 & 47.13 & 39.16 & 46.18 & 0.07 & 0.05 & 0.61 & 0.80 & 0.17 & 0.19 \\
\hline $6 \mathrm{P} 3$ & 0.60 & 0.50 & 0.64 & 0.52 & 39.53 & 51.05 & 38.77 & 50.26 & 0.12 & 0.27 & 0.64 & 0.78 & 0.15 & 0.18 \\
\hline $6 \mathrm{P} 4$ & 0.47 & 0.50 & 0.42 & 0.61 & 40.53 & 47.20 & 39.73 & 46.56 & 0.13 & 0.22 & 0.66 & 0.62 & 0.15 & 0.16 \\
\hline $8 \mathrm{P} 1$ & 17.22 & 17.40 & 1.23 & 0.85 & 43.16 & 38.13 & 42.32 & 37.08 & 0.04 & 0.33 & 0.80 & 0.65 & 0.11 & 0.11 \\
\hline $8 \mathrm{P} 2$ & 12.92 & 11.14 & 1.14 & 1.14 & 46.19 & 48.60 & 45.37 & 47.45 & 0.05 & 0.14 & 0.77 & 0.76 & 0.14 & 0.14 \\
\hline $8 \mathrm{P} 3$ & 21.96 & 18.66 & 0.90 & 0.28 & 42.46 & 38.75 & 41.74 & 37.68 & 0.07 & 0.38 & 0.65 & 0.59 & 0.15 & 0.11 \\
\hline $8 \mathrm{P} 4$ & 20.10 & 8.59 & 0.40 & 0.41 & 38.84 & 43.52 & 38.25 & 42.85 & 0.06 & 0.03 & 0.53 & 0.47 & 0.11 & 0.12 \\
\hline 9P1 & 1.08 & 1.61 & 1.83 & 1.27 & 45.48 & 36.84 & 43.99 & 35.76 & 0.01 & 0.09 & 1.48 & 1.01 & 0.13 & 0.10 \\
\hline 9P2 & 1.52 & 7.65 & 1.27 & 0.99 & 44.00 & 36.41 & 42.92 & 35.59 & 0.04 & 0.10 & 1.05 & 0.70 & 0.13 & 0.10 \\
\hline 9P3 & 4.06 & 12.71 & 1.00 & 0.71 & 39.89 & 32.71 & 38.87 & 31.80 & 0.10 & 0.33 & 0.92 & 0.60 & 0.14 & 0.10 \\
\hline $9 \mathrm{P} 4$ & 11.56 & 12.35 & 0.59 & 0.53 & 45.15 & 48.47 & 44.18 & 47.42 & 0.19 & 0.09 & 0.78 & 0.93 & 0.15 & 0.16 \\
\hline $10 \mathrm{P} 1$ & 0.45 & 0.35 & 1.46 & 1.55 & 31.54 & 31.40 & 30.32 & 30.22 & 0.09 & 0.20 & 1.13 & 1.12 & 0.09 & 0.09 \\
\hline 10P2 & 0.47 & 0.40 & 1.51 & 1.28 & 36.04 & 37.12 & 34.96 & 35.84 & 0.09 & 0.37 & 1.00 & 0.91 & 0.12 & 0.12 \\
\hline $10 \mathrm{P} 3$ & 0.40 & 0.80 & 0.98 & 1.00 & 33.03 & 34.90 & 32.16 & 33.95 & 0.12 & 0.17 & 0.75 & 0.80 & 0.13 & 0.12 \\
\hline $10 \mathrm{P} 4$ & 2.38 & 2.94 & 0.57 & 0.93 & 34.48 & 32.31 & 33.88 & 31.81 & 0.13 & 0.30 & 0.47 & 0.51 & 0.11 & 0.09 \\
\hline
\end{tabular}




\section{Çizelge 4- (Devam) Çalışılan toprakların gerçek ve tahmin edilen değerleri}

Table 4-Measured and predicted values of the studied soils (continuation of the table 4)

\begin{tabular}{|c|c|c|c|c|c|c|c|c|c|c|c|c|c|c|}
\hline \multirow{2}{*}{$\begin{array}{c}\text { Örnek } \\
\text { No }\end{array}$} & \multicolumn{2}{|c|}{$\mathrm{CaCO}_{3}$} & \multicolumn{2}{|c|}{ Org. $M$. } & \multicolumn{2}{|c|}{$K D K$} & \multicolumn{2}{|c|}{ Değ. $C a+M g$} & \multicolumn{2}{|c|}{ Değ. $N a$} & \multicolumn{2}{|c|}{ Değ. K } & \multicolumn{2}{|c|}{ COLE } \\
\hline & $M$ & $P$ & $M$ & $P$ & $M$ & $P$ & $M$ & $P$ & $M$ & $P$ & $M$ & $P$ & $M$ & $P$ \\
\hline $11 \mathrm{P} 1$ & 0.49 & 0.29 & 1.39 & 1.28 & 30.85 & 33.81 & 28.60 & 31.87 & 0.02 & 0.19 & 2.23 & 2.00 & 0.10 & 0.11 \\
\hline $11 \mathrm{P} 2$ & 0.44 & 0.63 & 0.83 & 0.86 & 32.72 & 27.21 & 30.15 & 25.92 & 0.05 & 0.03 & 2.51 & 1.57 & 0.09 & 0.09 \\
\hline $11 \mathrm{P} 3$ & 0.38 & 0.39 & 0.56 & 0.96 & 36.07 & 40.70 & 34.62 & 39.13 & 0.10 & 0.23 & 1.35 & 1.34 & 0.14 & 0.14 \\
\hline $11 \mathrm{P} 4$ & 0.42 & 0.00 & 0.39 & 0.48 & 39.30 & 40.23 & 38.49 & 39.34 & 0.19 & 0.21 & 0.62 & 0.56 & 0.14 & 0.14 \\
\hline $12 \mathrm{P} 1$ & 0.38 & 0.24 & 0.57 & 0.50 & 26.50 & 29.17 & 25.80 & 28.63 & 0.01 & 0.01 & 0.70 & 0.76 & 0.10 & 0.11 \\
\hline $12 \mathrm{P} 2$ & 0.38 & 0.44 & 0.26 & 0.11 & 24.79 & 28.60 & 24.37 & 28.48 & 0.03 & 0.02 & 0.39 & 0.20 & 0.08 & 0.10 \\
\hline $12 \mathrm{P} 3$ & 0.41 & 0.36 & 0.09 & 0.10 & 25.98 & 23.87 & 25.60 & 23.67 & 0.04 & 0.05 & 0.34 & 0.31 & 0.09 & 0.10 \\
\hline $12 \mathrm{P} 4$ & 0.36 & 0.95 & 0.10 & 0.10 & 22.66 & 26.71 & 22.36 & 26.62 & 0.05 & 0.03 & 0.25 & 0.21 & 0.10 & 0.11 \\
\hline $12 \mathrm{P} 5$ & 0.26 & 0.54 & 0.10 & 0.79 & 14.56 & 15.22 & 14.41 & 15.06 & 0.02 & 0.25 & 0.13 & 0.22 & 0.04 & 0.05 \\
\hline $13 \mathrm{P} 1$ & 12.86 & 18.40 & 2.51 & 2.00 & 52.10 & 51.78 & 50.15 & 49.76 & 0.00 & 0.14 & 1.94 & 1.73 & 0.11 & 0.12 \\
\hline $13 \mathrm{P} 2$ & 15.82 & 17.03 & 1.94 & 1.73 & 51.02 & 44.02 & 49.61 & 42.56 & 0.02 & 0.28 & 1.40 & 1.07 & 0.15 & 0.12 \\
\hline $13 \mathrm{P} 3$ & 23.04 & 17.07 & 0.72 & 1.32 & 51.76 & 46.55 & 50.76 & 44.95 & 0.06 & 0.36 & 0.93 & 1.07 & 0.14 & 0.13 \\
\hline $13 \mathrm{P} 4$ & 8.81 & 20.94 & 0.18 & 0.53 & 57.03 & 46.64 & 55.94 & 45.29 & 0.36 & 0.31 & 0.73 & 0.83 & 0.13 & 0.11 \\
\hline $13 \mathrm{P} 5$ & 18.68 & 11.82 & 0.77 & 0.92 & 54.02 & 45.70 & 53.08 & 44.99 & 0.41 & 0.18 & 0.53 & 0.24 & 0.14 & 0.11 \\
\hline $13 \mathrm{P} 6$ & 3.39 & 2.96 & 0.11 & 0.46 & 55.51 & 49.43 & 54.26 & 47.79 & 0.50 & 0.53 & 0.75 & 0.84 & 0.14 & 0.12 \\
\hline $14 \mathrm{P} 1$ & 0.56 & 0.63 & 0.77 & 1.26 & 19.85 & 24.81 & 19.36 & 23.90 & 0.01 & 0.18 & 0.48 & 0.98 & 0.06 & 0.07 \\
\hline $14 \mathrm{P} 2$ & 0.52 & 0.55 & 0.59 & 0.57 & 24.51 & 27.87 & 24.15 & 27.69 & 0.02 & 0.05 & 0.34 & 0.31 & 0.07 & 0.09 \\
\hline $14 \mathrm{P} 3$ & 0.38 & 0.62 & 0.48 & 0.28 & 31.71 & 32.91 & 31.41 & 32.41 & 0.04 & 0.06 & 0.26 & 0.44 & 0.11 & 0.12 \\
\hline $14 \mathrm{P} 4$ & 0.59 & 0.22 & 0.50 & 0.40 & 39.75 & 45.53 & 39.26 & 44.88 & 0.11 & 0.09 & 0.38 & 0.51 & 0.15 & 0.15 \\
\hline 15P1 & 0.77 & 0.77 & 1.35 & 1.14 & 32.99 & 34.53 & 32.74 & 34.03 & 0.03 & 0.11 & 0.22 & 0.35 & 0.07 & 0.09 \\
\hline $15 \mathrm{P} 2$ & 0.50 & 0.41 & 0.43 & 0.57 & 36.87 & 41.57 & 35.15 & 40.20 & 1.58 & 0.89 & 0.14 & 0.23 & 0.09 & 0.11 \\
\hline $15 \mathrm{P} 3$ & 0.59 & 0.73 & 0.18 & 0.29 & 36.39 & 35.76 & 34.40 & 34.18 & 1.88 & 1.07 & 0.11 & 0.39 & 0.08 & 0.11 \\
\hline $15 \mathrm{P} 4$ & 1.62 & 1.19 & 0.12 & 0.46 & 34.85 & 31.14 & 34.64 & 30.94 & 0.13 & 0.02 & 0.08 & 0.23 & 0.08 & 0.08 \\
\hline 16P1 & 0.32 & 2.80 & 2.41 & 2.33 & 15.42 & 21.90 & 15.27 & 21.56 & 0.01 & 0.14 & 0.14 & 0.43 & 0.00 & 0.03 \\
\hline $16 \mathrm{P} 2$ & 0.29 & 3.34 & 0.66 & 0.68 & 13.00 & 19.58 & 12.70 & 19.39 & 0.01 & 0.03 & 0.29 & 0.43 & 0.01 & 0.05 \\
\hline $16 \mathrm{P} 3$ & 0.43 & 5.14 & 0.24 & 0.20 & 17.21 & 18.36 & 16.98 & 18.31 & 0.03 & 0.26 & 0.20 & 0.63 & 0.03 & 0.05 \\
\hline $16 \mathrm{P} 4$ & 0.45 & 0.22 & 0.17 & 0.60 & 13.51 & 18.37 & 13.31 & 18.07 & 0.11 & 0.34 & 0.09 & 0.19 & 0.02 & 0.05 \\
\hline 17P1 & 31.96 & 28.77 & 2.15 & 1.99 & 36.91 & 33.10 & 35.19 & 31.28 & 0.29 & 0.40 & 1.43 & 1.60 & 0.05 & 0.06 \\
\hline $17 \mathrm{P} 2$ & 50.99 & 34.48 & 0.98 & 1.16 & 25.46 & 35.81 & 23.60 & 33.94 & 0.54 & 0.64 & 1.32 & 1.28 & 0.10 & 0.10 \\
\hline 17P3 & 68.12 & 46.09 & 0.84 & 1.39 & 19.84 & 16.96 & 17.55 & 14.79 & 1.42 & 1.26 & 0.86 & 1.30 & 0.10 & 0.07 \\
\hline $17 \mathrm{P} 4$ & 44.88 & 41.91 & 0.36 & 0.45 & 15.40 & 25.22 & 13.75 & 23.82 & 1.24 & 1.14 & 0.41 & 0.33 & 0.06 & 0.09 \\
\hline $17 \mathrm{P} 5$ & 64.63 & 45.08 & 0.27 & 0.82 & 23.65 & 21.21 & 20.75 & 18.84 & 2.19 & 1.63 & 0.71 & 0.97 & 0.13 & 0.08 \\
\hline
\end{tabular}


Kil miktarı; ortalama \% 46.49, minimum \% 14.86 ve maksimum \% 77.42 olarak bulunmuştur. Çalışmada $\mathrm{R}^{2}=0.59$ 'luk bir başarı elde edilmiş ve Şekil 2'de verilmiştir. Chang et al (2001), kil miktarını belirlemeye yönelik çalışmasında toplam 149 örneğin 30 tanesini kalibrasyon için kullanmış, PCA (temel bileşenler analizi) ile VIS-NIR bölgede (400-2498 nm) $R^{2}=0.67$ 'lik bir başarı sağlamıştır. Shepherd \& Walsh (2002), 457 adet örneğin 152 tanesini validasyon setin de olmak üzere istatistik analizi olarak MARS (çok değişkenli uyarlanabilir regresyon eğrileri) kullanarak VIS-NIR bölgede $(350-2500 \mathrm{~nm}) \mathrm{R}^{2}=0.78$ elde etmiştir. NIR bölgeye yönelik ise Islam et al (2003) PCR ile (700-2500 nm) $\mathrm{R}^{2}=0.75$ 'i 161 adet toprak örneğinde elde etmiştir. MIR'a (Orta kızı̈ötesi yansıma spektroskopisi) yönelik kil miktar tayini çalışmalarında daha yüksek sonuçlar elde edilmiştir. Janik et al (1998), 2500-25000 nm aralığında PLSR (kısmi en küçük kareler regresyonu) ile $\mathrm{R}^{2}=0.79$ bulurken, Janik \& Skjemstad (1995), 2500-20000 nm aralı̆̆ında PLSR ile $\mathrm{R}^{2}=0.87^{\prime}$ lik tahmin başarısı elde etmişlerdir. Chang et al (2001) çalışmasına benzer dalga boyu ve istatistiksel analizler yapılmasına karşın araştırıcılar veri setini minumum $\% 0.7$ ve maksimum $\% 35.2^{\prime}$ lik kil miktarına sahip örnekler üzerinde yapmıştır.

Silt miktarı ortalama \% 25.83, minimum \% 9.03 ve maksimum \% 55.79 olarak belirlenmiştir. Silt içeriğini belirlemeye yönelik çalışmalar VISNIR bölgede yoğunlaşmıştır. Cozzolino \& Moron (2003), 317 adet örnek üzerinde yaptıkları çalışmada Modified-PLSR (modifiye- kısmi en küçük kareler regresyonu) istatistik analizi ile \% 18-74 aralığındaki silt içeriğine sahip örneklerde 0.80 'lik bir başarı elde etmişlerdir. Islam et al (2003), UV-VIS-NIR bölgede 161 örnek (kalibrasyon, 121) üzerinde PCR istatistik analiz yöntemini kullanarak çok düşük bir başarı elde etmiş, sebep olarak silt içeriğinin $\%<0.01-40.0$ aralığında olması ve UV bölgenin çalışmanın başarı oranını düşürdüğüne dikkat çekmişlerdir. Bu sonuç yapılan çalışmaya paralellik göstermiş \% 9.03-\%55.79 aralığındaki topraklarda, VIS-NIR bölgelerde uygulanan yöntemin yeterli sonuçlar vermediği ve $\mathrm{R}^{2}=0.46$ 'lık zayıf bir başarı elde edildiği görülmüştür (Şekil 3).
Chang et al (2001) ve Cozzolino \& Moron (2003) VIS-NIR bölgede $\mathrm{R}^{2}=0.84$ ve $\mathrm{R}^{2}=0.80$ 'lik başarı elde etmişlerdir. Cozzolino ve Moron (2003) başarıda silt içeriğinin geniş olması gerektiğine (\% 40-80) ve değerlendirmede kullanılan bölgenin önemine vurgu yapmışlardır. Kum miktarı da, kil ve silt miktarlarına benzer şekilde geniş bir dağılım sunmuştur. Ortalama kum miktarı \% 27.48 , minimum \% 6.45 ve maksimum \% 64.61

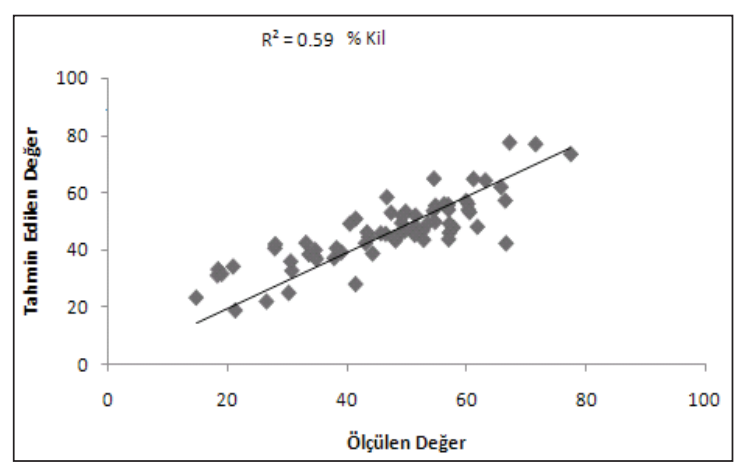

Şekil 2- Yakın kızılötesi yansıma spektroskopisi ile tahmin edilen ve standart laboratuvar metotlar ile ölçülen kil arasındaki ilişki

Figure 2- Relationship between clay measured by standard laboratory procedures and predicted by NIRS technique

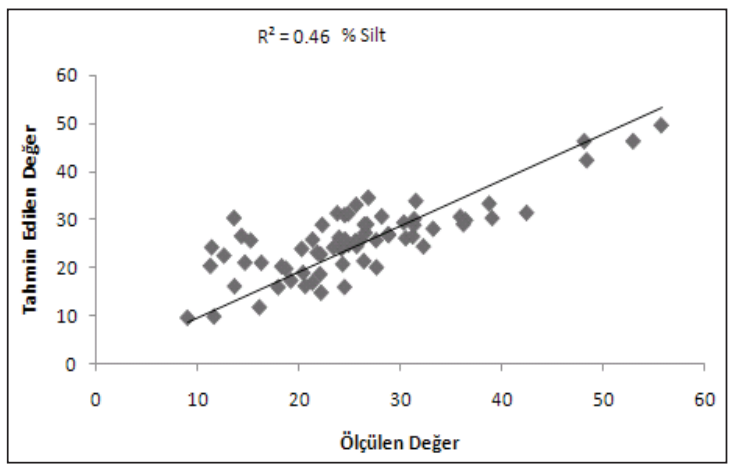

Şekil 3- Yakın kızılötesi yansıma spektroskopisi ile tahmin edilen ve standart laboratuvar metotlar ile ölçülen silt arasındaki ilişki

Figure 3- Relationship between silt measured by standard laboratory procedures and predicted by NIRS technique 


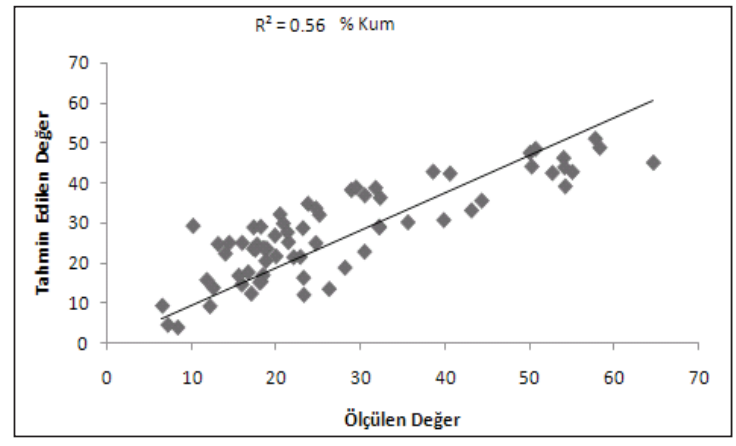

Şekil 4- Yakın kızılötesi yansıma spektroskopisi ile tahmin edilen ve standart laboratuvar metotlar ile ölçülen kum arasındaki ilişki

Figure 4- Relationship between sand measured by standard laboratory procedures and predicted by NIRS technique

olarak bulunmuştur. Kum boyutunu belirlemeye yönelik ise MIR bölgede yapılan çalışmalar gayet iyi sonuçlar vermiştir. Janik et al (1998), 88 örnek üzerinde PLSR istatistik analizi ile 2500-25000 nm dalga boyu aralıklarında $\mathrm{R}^{2}=0.84$ 'lük tatmin edici bir başarı ortaya koymuştur. Islam et al (2003), UV-VIS-NIR bölgede $\mathrm{R}^{2}=0.53$ 'lük düşük bir başarı elde etmiş, başarısızlıkta etken rolün \% 8.3-98.3 geniş bir aralığa sahip kum boyutlu malzemenin etken rol oynadığını belirtmişlerdir. Kum boyutunu belirlemeye yönelik çalışmada Islam et al (2003)'ün sonuçlarına yakın değerler elde edilerek $\mathrm{R}^{2}=0.56$ ' lık zayıf bir başarı ortaya konmuştur (Şekil 4). Sebep olarak \% 6.45-64.61 aralığındaki kum boyutu ve kullanılan VIS-NIR bölge gösterilebilir.

Chang et al (2001) VIS-NIR bölgede (400-2498 nm) PCR ile 0.84'lik bir başarı elde etmişler fakat farklı elek boyutlarına sahip materyal üzerinde yaptıkları çalışmada $8 \mathrm{~mm}$ elek boyutuna sahip örnek üzerinde bu başarının elde edildiğini belirtmişlerdir.

Toprak tekstürü ile yakın ilişki halinde bulunan tarla kapasitesi ve solma noktası sonuçları geniş bir dağılım sunmuştur. Tarla kapasitesi değeri ortalama $\%$ 28.91, minimum \% 15.62 ve maksimum $\% 55.16$ olarak bulunmuştur. Ortalama solma noktası değeri $\%$ 18.81, minimum \% 5.64 ve maksimum \% 31.42 olarak bulunmuştur. Sudduth \& Hummel (1991)

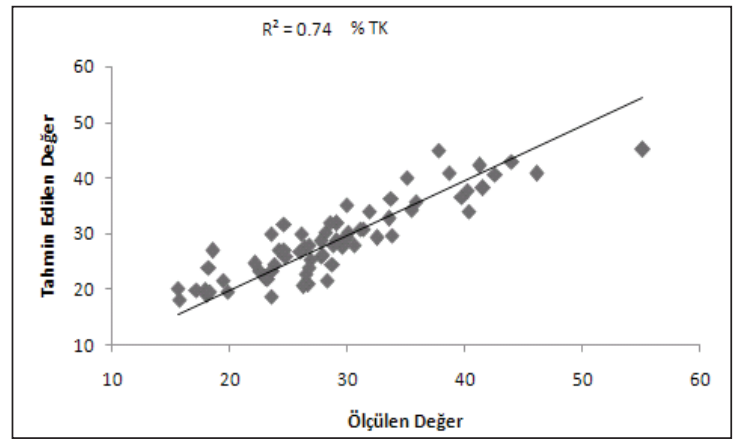

Şekil 5- Yakın kızılötesi yansıma spektroskopisi ile tahmin edilen ve standart laboratuvar metotlar ile ölçülen tarla kapasitesi (TK) arasındaki ilişki

Figure 5-Relationship between field capacity measured by standard laboratory procedures and predicted by NIRS technique

farklı organik madde içeriğine sahip topraklarda $1720-2380 \mathrm{~nm}$ dalga boyu aralığında $60 \mathrm{~nm}$ aralıklar ile toplam 12 dalga boyunda İllionis (USA)'de 30 adet toprakta tarla kapasitesi ve solma noktasinın tahmin edilmesinde $\mathrm{R}^{2}=0.92$ 'lik başarı elde etmişlerdir. Chang et al (2001) solma noktasinı belirlemeye yönelik çalışmasında $0.01-0.62 \mathrm{~kg} \mathrm{~kg}^{-1}$ aralığındaki toplam 743 örnek üzerinde $\mathrm{R}^{2}>0.80$ 'lik bir başarı elde etmiştir. Yapılan çalışma sonucunda tarla kapasitesi $\mathrm{R}^{2}=0.74$ ve solma noktasi ise $\mathrm{R}^{2}=0.67^{\prime}$ lik bir tahmin başarısı göstermiştir (Şekil 5-6).

Çalışma toplam 57 adet toprak örneği üzerinde yürütülmüş, kütle yoğunluğu miktarları geniş bir dağılım sunmuştur. Ortalama kütle yoğunluğu miktar1 $1.407 \mathrm{~g} / 100 \mathrm{~cm}^{3}$, minimum $1.050 \mathrm{~g} / 100 \mathrm{~cm}^{3}$ ve maksimum $1.898 \mathrm{~g} / 100 \mathrm{~cm}^{3}$ olarak bulunmuştur. Moreira et al (2009), kütle yoğunluğu belirlemeye yönelik çalışmasında 250-1000 nm dalga boyu aralığını kullanmıştır. Toplam 1184 örnek üzerindeki çalışmada kullanılan örnekler $0.45-1.95 \mathrm{~g} \mathrm{~cm}^{-3}$ aralığındadır. Geniş bir aralığa dağılmış örnekler üzerindeki yaptığı çalışma sonunda $\mathrm{R}^{2}=0.14$ ile çok düşük bir performans elde etmişlerdir. Çalışmada elde edilen veriler sonucunda $1.05-1.90 \mathrm{~g} \mathrm{~cm}^{-3}$ aralığına sahip örneklere uygulanan istatistik analiz sonucunda $\mathrm{R}^{2}=0.70$ ile tatmin edici sonuçlar elde edilmiştir (Şekil 7). 


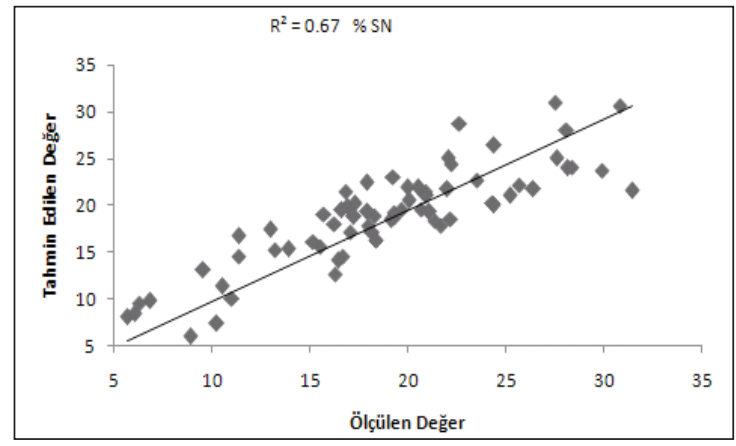

Şekil 6- Yakın kızılötesi yansıma spektroskopisi ile tahmin edilen ve standart laboratuvar metotlar ile ölçülen solma noktası (SN) arasındaki ilişki

Figure 6-Relationship between wilting point measured by standard laboratory procedures and predicted by NIRS technique

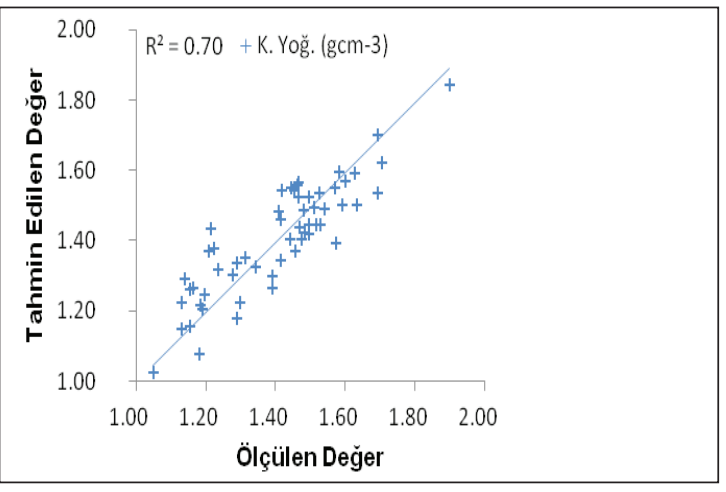

Şekil 7- Yakın kızıötesi yansıma spektroskopisi ile tahmin edilen ve standart laboratuvar metotlar ile ölçülen kütle yoğunluğu arasındaki ilişki

Figure 7-Relationship between bulk density measured by standard laboratory procedures and predicted by NIRS technique

Yansıma spektroskopisi çalışmalarında toprak nem ve kil miktarı, organik karbon ve demir gibi özellikleri doğrudan belirlenirken, $\mathrm{pH}$ gibi parametrelerin belirlenmesi dolaylı yollardan yapılmaktadır. Bu nedenle $\mathrm{pH}$ ve yansıma arasındaki ilişkiler düşük bulunmuştur. Ortalama $\mathrm{pH}$ (su) ve $\mathrm{pH}$ ( $\mathrm{KCl})$ değerleri sırası ile 7.06, 6.44, minimum 4.19, 3.66 ve maksimum $8.57,7.69$ olarak bulunmuştur. Islam et al (2003), pH (toprak:su) tahminine yönelik

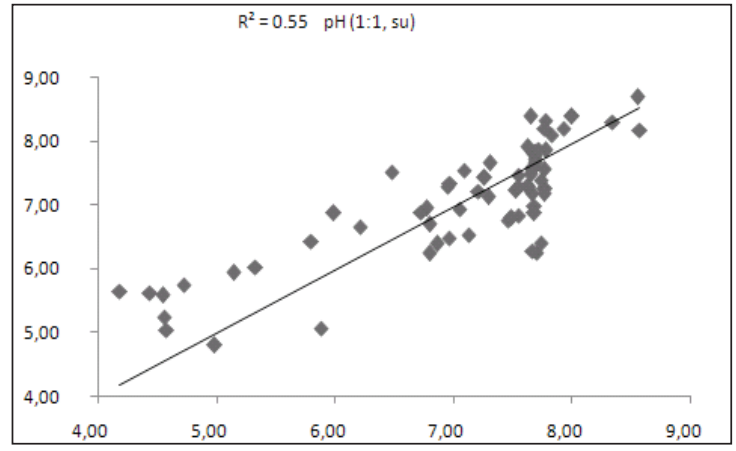

Şekil 8- Yakın kızılötesi yansıma spektroskopisi ile tahmin edilen ve standart laboratuvar metotlar ile ölçülen pH $(1: 1$, su) arasındaki ilişki

Figure 8- Relationship between $p H$ (1:1, water) measured by standard laboratory procedures and predicted by NIRS technique

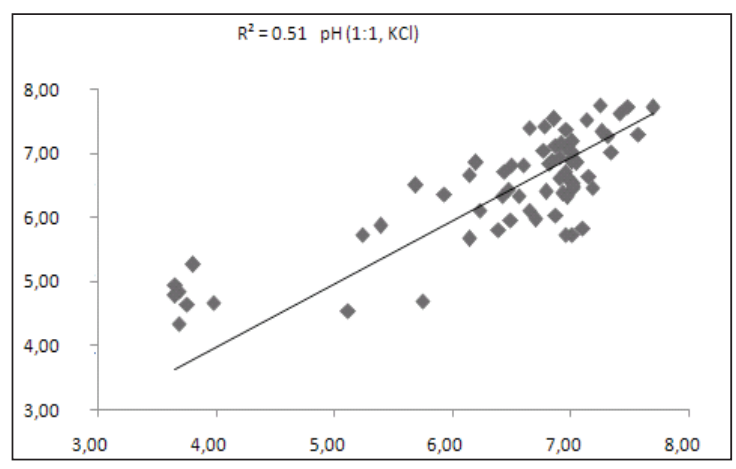

Şekil 9- Yakın kızılötesi yansıma spektroskopisi ile tahmin edilen ve standart laboratuvar metotlar ile ölçülen pH $(1: 1, \mathbf{K C l})$ arasındaki ilişki

Figure 9- Relationship between $p H(1: 1, \quad \mathrm{KCl})$ measured by standard laboratory procedures and predicted by NIRS technique

çalışmasında iki ayrı spektral bölgeyi (NIR, UVVIS-NIR) değerlendirmiş, sonuçta $\mathrm{R}^{2}=0.70$ 'lik bir başarı elde etmiştir. Chang et al (2001), Shibusawa et al (2001) $\mathrm{R}^{2}=0.57-0.54$ 'lük bir tahmin düzeyleri elde etmişlerdir. Bu literatürdeki sonuçlar yapılan çalışma ile uyumluluk göstermiş, gerek toprak:su $(1: 1) \quad\left(\mathrm{R}^{2}=0.55\right)$ ve gerekse $\mathrm{KCl}(1: 1) \quad\left(\mathrm{R}^{2}=0.51\right)$ ile tahmin edilen değerlere yakın sonuçlar elde edilmiştir (Şekil 8-9). 


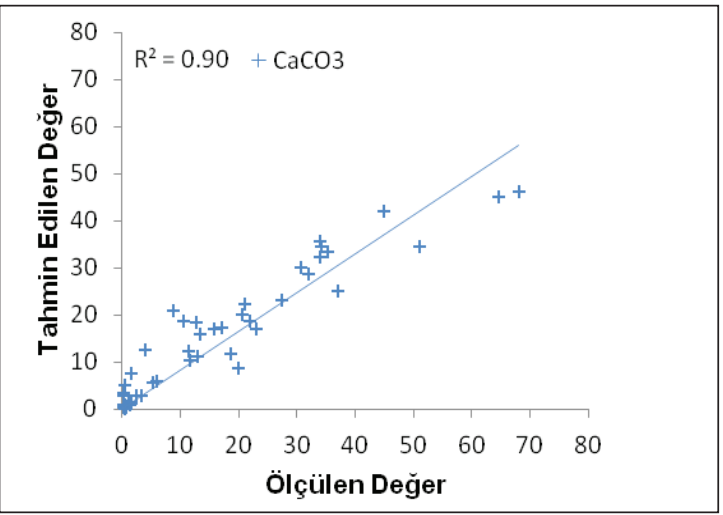

Şekil 10- Yakın kızılötesi yansıma spektroskopisi ile tahmin edilen ve standart laboratuvar metotlar ile ölçülen kireç arasındaki ilişki

Figure 10- Relationship between lime measured by standard laboratory procedures and predicted by NIRS technique

Çalışmadaki ortalama kireç içeriği \% 11.41, minimum \% 0.26 ve maksimum \% 68.22 olarak belirlenmiştir. Ben-Dor \& Banin (1995) MRA (çoklu regresyon analizi) ile 1000-2500 nm aralığında kireç içeriğini 0.69 , Janik et al (1998) NIR bölgede 0.73 , MIR bölgede 0.86 ve Janik \& Skjemstad (1995) MIR bölgede 0.95'lik değerleri tahmin etmişlerdir. Literatür çalışmaya uygunluk göstermiş, $\mathrm{R}^{2}=0.90^{\prime}$ 'lık tahmin başarısı önemli bulunmuş̧ur (Şekil 10).

Genel olarak çalışma alanı içerisindeki toprakların organik madde içerikleri yüzeyden itibaren azalan bir eğilim sunmuş ve geniş bir yayılıma sahip olmuştur. Ortalama organik madde içeriği $\% 0.90$, minimum $\% 0.08$ ve maksimum \% 3.99 olarak belirlenmiştir. Daniel et al (2003) NN (yapay sinir ağları) ile VIS-NIR bölgede 0.86 , BenDor \& Banin (1995) MRA ile NIR bölgede 0.55, Masserschmidt et al (1999) PLSR ile MIR bölgede $0.98^{\prime}$ lik tahmin edilebilirliğini ortaya koymuşlardır. Literatürlerde kullanılan bölge ve istatistik yöntemlerdeki farklılıklar belirlenme olasılığını değiştirmektedir. Çalışmaya en yakın Ben-Dor \& Banin (1995)'in elde ettiği sonuçlar olmuş $\left(\mathrm{R}^{2}=0.57\right)$ aynı şekilde gerek bölge ve gerek ise

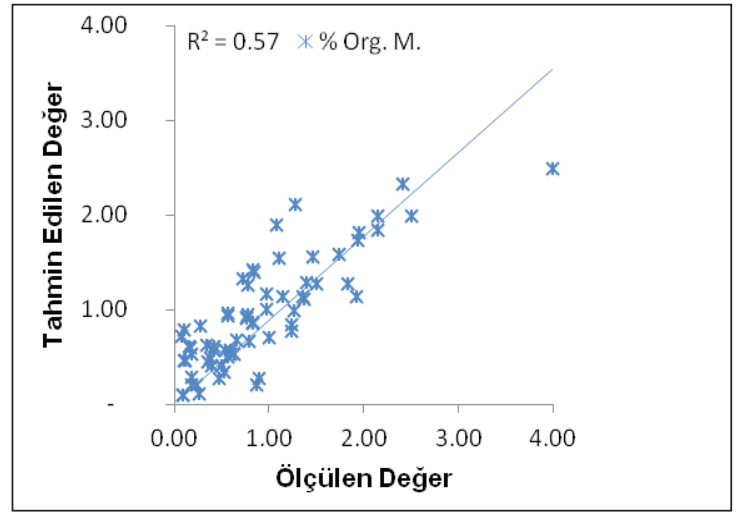

Şekil 11- Yakın kızılötesi yansıma spektroskopisi ile tahmin edilen ve standart laboratuvar metotlar ile ölçülen organik madde arasındaki ilişki

Figure 11- Relationship between organic matter measured by standard laboratory procedures and predicted by NIRS technique

istatistik analiz yönteminin yakın olması sonuçların uyumluluğunu ortaya koymuştur (Şekil 11). Fakat organik madde içeriğini tahmin etmede kullanılan istatistik yöntemin uygun olmadığı ortaya çıkmıştır.

Geniş bir aralıkta yayılım sunan katyon değişim kapasitesinin ortalama miktarı $34.81 \mathrm{me} / 100 \mathrm{~g}$, minimum $13.00 \mathrm{me} / 100 \mathrm{~g}$ ve maksimum 57.83 me $/ 100 \mathrm{~g}$ olarak belirlenmiştir. Islam et al (2003) UV-VIS-NIR ve NIR bölgelerde PCR ile 0.64 ve 0.67 , Ben-Dor \& Banin (1995) 1000-2500 nm aralığında MRA ile $\mathrm{R}^{2}=0.64$, Chang et al (2001) VIS-NIR bölgede PCR ile 0.81'lik tahmin başarıs1 elde etmişlerdir. Yapılan çalışma ile Islam et al (2003) tarafından yürütülen araştırmanın sonuçları benzerlik göstermiştir ve \% 65'lik bir tahmin başarısı elde edilmiştir (Şekil 12).

Değişebilir katyonlardan bir kısmının $\mathrm{Ca}$ miktarının yüksek bulunması nedeni ile KDK miktarından $\mathrm{Na}$ ve $\mathrm{K}$ miktarlarının çıkarılması ile $\mathrm{Ca}+\mathrm{Mg}$ değerleri elde edilmiştir. Değişebilir $\mathrm{Ca}$ miktarlarının düşük olan örneklemelerde ise belirlenen $\mathrm{Ca}$ ve $\mathrm{Mg}$ değerlerinin toplanması yoluna gidilmiştir. $\mathrm{Bu}$ nedenle yansıma ile $\mathrm{Ca}$ ve $\mathrm{Mg}$ değerleri toplam halde belirlenmeye çalışılmıştır. Geniş bir aralıkta yayılım sunan $\mathrm{Ca}+\mathrm{Mg}$ ortalama 


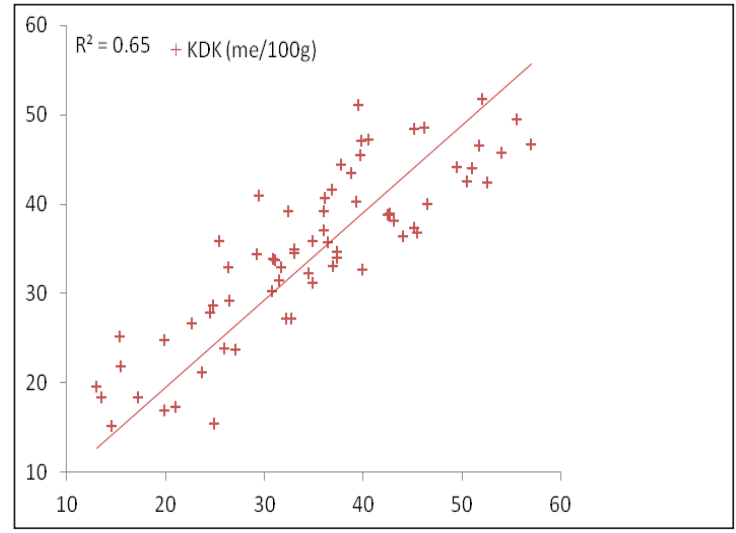

Şekil 12- Yakın kızılötesi yansıma spektroskopisi ile tahmin edilen ve standart laboratuvar metotlar ile ölçülen katyon değişim kapasitesi (KDK) arasındaki ilişki

Figure 12- Relationship between cation exchange capacity (CEC) measured by standard laboratory procedures and predicted by NIRS technique

miktar1 $33.89 \mathrm{me} / 100 \mathrm{~g}$, minimum $12.70 \mathrm{me} / 100 \mathrm{~g}$ ve maksimum $55.94 \mathrm{me} / 100 \mathrm{~g}$ olarak belirlenmiştir. Hava kuru olarak alınan yansıma ölçümlerinde $\mathrm{Ca}+\mathrm{Mg}$ ile yansıma arasında $\mathrm{R}^{2}=0.64$ 'lük bir ilişki tespit edilmiş ve Şekil 13 'de verilmiştir. Chang et al (2001) ve Shepherd \& Walsh (2002), değişebilir kalsiyum miktarını sirası ile $\mathrm{R}^{2}=0.75$ ve $\mathrm{R}^{2}=0.88$ başarı oranı ile tespit ettiklerini belirtmişlerdir. Aynı araştırıcılar çalışmalarında değişebilir magnezyum değerini $\mathrm{R}^{2}=0.68$ ile $\mathrm{R}^{2}=0.81$ arasında değişim gösterdiğini bildirmişlerdir.

Shepherd \& Walsh (2002)'ın yaptıkları çalışmada istatistiksel analiz olarak MARS kullanılırken, Chang et al (2001)'ın yaptıkları çalışmada ise dalga boyu aralığı 400-2498 nm olarak kullanılmıştır. Yapılan çalışma da elde edilen değerin bu nedenli düşük olması kullanılan yöntem ve seçilen dalga boyu aralığının farklı olması gösterilebilir. Değişebilir $\mathrm{K}$ ve $\mathrm{Na}$ içerikleri düşük ve dar bir alanda yayılım sunmuşlardır. Ortalama miktarları sirası ile $0.68,0.23 \mathrm{me} / 100 \mathrm{~g}$, minimum $0.08,0.00$ me $/ 100 \mathrm{~g}$ ve maksimum 2.51 ve $2.19 \mathrm{me} / 100 \mathrm{~g}$ olarak belirlenmiştir. Yansıma ölçümlerinde $\mathrm{K}$ ve

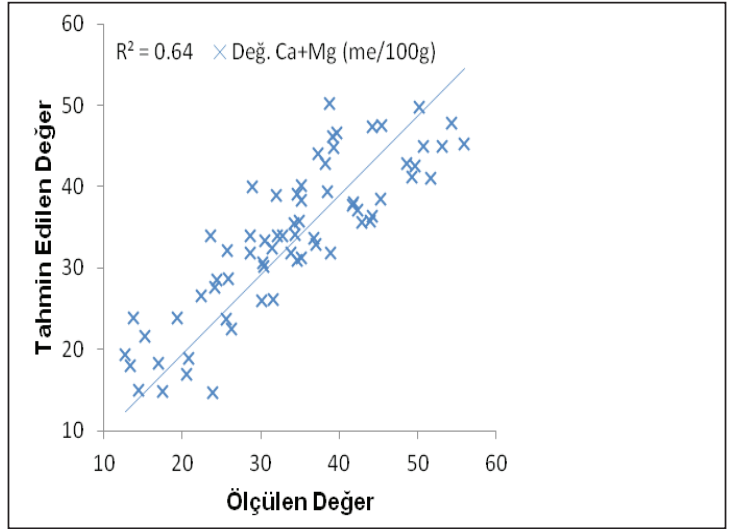

Şekil 13- Yakın kızılötesi yansıma spektroskopisi ile tahmin edilen ve standart laboratuvar metotlar ile ölçülen değişebilir $\mathbf{C a}+\mathbf{M g}$ arasındaki ilişki

Figure 13- Relationship between exchangeable $\mathrm{Ca}+\mathrm{Mg}$ measured by standard laboratory procedures and predicted by NIRS technique

Na değerleri ile yansıma arasında sırasıyla $\mathrm{R}^{2}=0.66$, 0.58 'lik bir ilişki tespit edilmiş ve Şekil 14 ve 15 'de verilmiştir. Değişebilir K içeriğine yönelik, Chang et al (2001) 0.55'lik bir tahmin başarısı (16.2$1757.2 \mathrm{mg} \mathrm{kg}^{-1}$ ), Janik et al (1998) MIR bölgede olmasına rağmen $\mathrm{R}^{2}=0.33$ 'lük bir tahmin başarıları elde etmişlerdir. Yapılan çalışma sonucu literatürden daha iyi bir tahmin başarısı edilmesi $\left(\mathrm{R}^{2}=0.66\right)$ gerek çalışma aralığının dar olmasına (0.08-2.51 me/100 gr) ve gerekse kullanılan bölge ve istatistiksel analizin doğruluğunu ortaya koymaktadır.

Değişebilir $\mathrm{Na}$ içeriğine yönelik çalışmalarda, Cozzolino \& Moron (2010), veri setini ikiye ayırmış $0.053 \mathrm{~mm}$ (silt+kil) ve kum $(0.212 \mathrm{~mm})$ fraksiyonlarda tahmin başarısını ortaya koymaya çalışmış, $0.15-1 \mathrm{me} / 100$ gr $\mathrm{Na}$ içeriğine sahip topraklarda PCR ve PLS istatistik analizleri uygulamış, yapılan analizler sonucunda sırası ile PLS için 0.42 ve 0.77 , PCR için 0.54 ve 0.80 'lik bir tahmin başarısı elde etmişlerdir. Zornoza et al (2008) 800-2600 nm dalga boyu aralığında $2 \mathrm{~mm}$ elekten geçmiş toprakta yapılan çalışma sonucu 0.13'lük bir tahmin elde edebilmişlerdir. Yapılan 


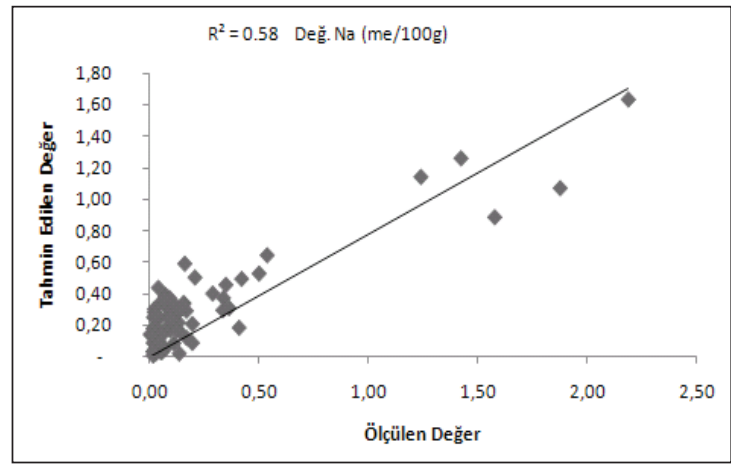

Şekil 14- Yakın kızılötesi yansıma spektroskopisi ile tahmin edilen ve standart laboratuvar metotlar ile ölçülen değişebilir Na arasındaki ilişki

Figure 14- Relationship between exchangeable $\mathrm{Na}$ measured by standard laboratory procedures and predicted by NIRS technique

çalışmada 0.58'lık başarı Zornoza et al (2008)'ın tahmin başarısının üzerinde bulunmuştur. Fakat, Cozzolino \& Moron (2010) tarafindan yapılan çalışmada sodyumun belirlenmesinde partikül boyutunun önemine vurgu yapılmıştır. $\mathrm{Bu}$ nedenle elek boyutunun bu tip çalışmalarda önemli olduğu ortaya çıkmış ve tahmin başarısını yükseltmek için örneklerin $2 \mathrm{~mm}$ ve üzerinde elekler kullanılarak hazırlanması gerektiği anlaşılmıştır.

Toprakta şişme büzülme potansiyelini ortaya koyan COLE değeri, minimum 0.003 ve maksimum 0.174 olarak bulunmuştur. Minasy et al (2008), ortalama \% 34 kil içeriğine sahip toplam 777 adet toprak örneğinde COLE değerini \% 53'lük bir tahmin başarısı ile elde ettiğini belirtmiştir. Yapılan çalışmada ise Minasy et al (2008)'e paralellik göstererek $\mathrm{R}^{2}=0.50$ olarak belirlenmiştir (Şekil 16).

\section{Sonuçlar}

Kızılötesi yansıma spektroskopisi ile toprak özelliklerinin belirlenmesine yönelik yapılan çalışmalar Türkiye'de yeni olmasına karşılık dünyada çok yaygındır. Brezilya, ABD ve Danimarka gibi pek çok ülke spektroskopik kütüphaneler oluşturmakta ve geniş veri ağlarında

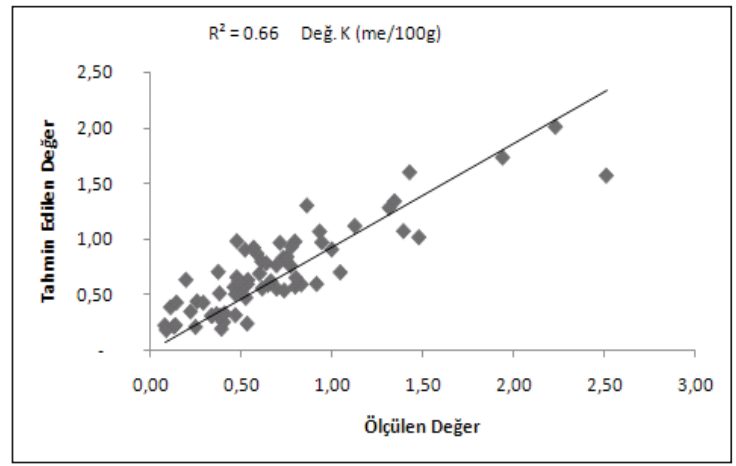

Şekil 15- Yakın kızıötesi yansıma spektroskopisi ile tahmin edilen ve standart laboratuvar metotlar ile ölçülen değişebilir $\mathbf{K}$ arasındaki ilişki

Figure 15- Relationship between exchangeable $K$ measured by standard laboratory procedures and predicted by NIRS technique

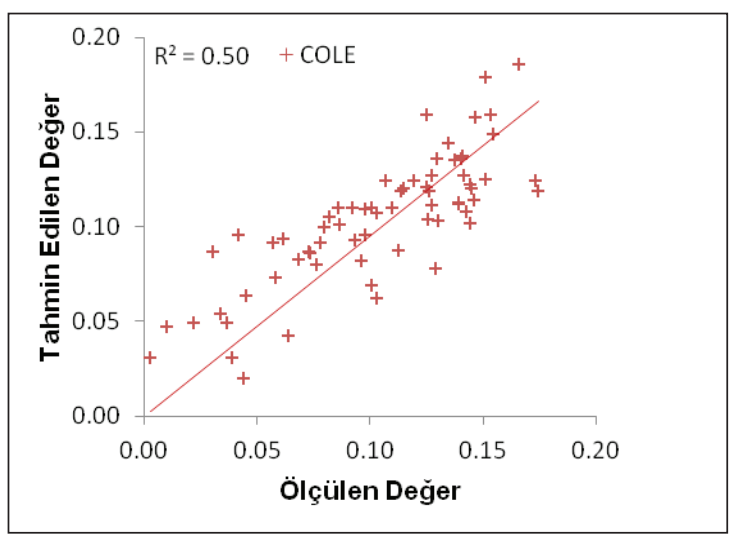

Şekil 16- Yakın kızılötesi yansıma spektroskopisi ile tahmin edilen ve standart laboratuvar metotlar ile ölçülen doğrusal genişleme katsayısı (COLE) arasındaki ilişki

Figure 16- Relationship between coefficient of linear extensibility (COLE) measured by standard laboratory procedures and predicted by NIRS technique

çalışmalar yapmaktadır. Bu tür çalışmaların yeni olması nedeni ile kullanılan bölge ve istatistiki yöntemlerin önemine vurgu yapılmaktır.

Çalışma da bazı toprak özellikleri ile yansıma değerleri arasındaki ilişkiler ortaya konmuştur. Yansıma değerleri ile çalışılan toprak parametreleri 
arasındaki ilişkiler sırasıyla kil $\mathrm{R}^{2}=0.59$, silt $\mathrm{R}^{2}=0.46$, kum $\mathrm{R}^{2}=0.56$, tarla kapasitesi $\mathrm{R}^{2}=0.74$, solma noktası $\mathrm{R}^{2}=0.67$, kütle yoğunluğu $\mathrm{R}^{2}=0.70$, $\mathrm{pH}\left(1: 1\right.$, toprak:su) $\mathrm{R}^{2}=0.55, \mathrm{pH}(1: 1$, toprak: $\mathrm{KCl})$ $\mathrm{R}^{2}=0.51$, kireç $\mathrm{R}^{2}=0.90$, organik madde $\mathrm{R}^{2}=0.57$, KDK $\mathrm{R}^{2}=0.65$, değişebilir katyonlar $\mathrm{R}^{2}=0.58-0.66$ ve COLE değeri $\mathrm{R}^{2}=0.50$ olarak belirlenmiştir. Genel olarak, yapılan çalışmada toprak fiziksel özelliklerini belirleme katsayıları yüksek bulunurken, kil tipini doğrudan etkileyen kimyasal özellikler, yöntemin doğrudan belirleme imkanı göstermemesi nedeniyle, düşük bulunmuştur. Fakat KDK, DK (değişebilir katyonlar) gibi zor ve zaman alıcı kimyasal analizlerin belirlenmesinde yakın sonuçlar vermesi metodun geçerli olabileceğini ortaya koymaktadır.

Kızılötesi yansıma spektroskopisi çalışmaları ülkemiz açısından yenidir. $\mathrm{Bu}$ nedenle geniş bir veri setinin oluşturulması çabasına gidilmelidir. İstatistiki olarak yöntem bazında ise tam bir metot oluşturulmamıştır. Farklı istatistik metotlar ile de farklı başarı oranları ortaya çıkmaktadır. Çalışmada toprak özelliklerinin belirlenebilmesi, yeterli bir veri seti olmasa da yöntemin uygulanabilirliğini ortaya koymuştur. Fakat örnekleme bazında sayının artırılması ile geniş bir veri setinde çalışmalar yapılarak metodun çalışılabilirliği ortaya konmuştur. Küçük ölçekte yapılan çalışmaların bir araya getirilmesi ve yansıma spektroskopisi veri kütüphanesinin oluşturulması, ülke bazında veri tabanının oluşturulmasına katkıda bulunacaktır.

\section{Teşekkür}

$\mathrm{Bu}$ araştırma makalesi, Süleyman Demirel Üniversitesi tarafindan desteklenen 2080-D-09 numaralı doktora projesinin bir kısmıdır.

\section{Kaynaklar}

Alcicek H (2009). Late Miocene Nonmarine Sedimentation and Formation of Magnesites in The Acıgöl Basin, Southwetern Anatolia, Turkey. Sedimentary Geology 219: $115-135$

Altınbaş Ü, Kurucu Y \& Bolca M (2001). Ege Bölgesi ve Çevresinin 2000 Yılına Ait Pamuk Ekili Alanları ve
Pamuk Ürün Rekoltesinin Uzaktan Algılama Tekniği - Uydu Verileri ile Saptanması Üzerine Araştırmalar. 2000 BİL 030 No' lu Ege Üniversitesi Araştırma Fonu Projesi. Bornova, İzmir

Anonymous (1951). Soil Survey Manual. Soil Survey Staff, USDA. Handbook, 18

Anonymous (1973). Analytical Methods for A.A. Spektrometry. Perkin Elmer. Norwalk, Connecticut, USA

Batten G D (1998). Plant Analysis Using Near-Infrared Reflectance Spectroscopy. The Potential and Limitations Australian Journal of Experimental Agriculture 38: 697-706

Ben-Dor E \& Banin A (1995). Near-Infrared Analysis as A Rapid Method to Simultaneously Evaluate Several Soil Properties. Soil Science Society of America Journal 59: 364- 372

Blake G R \& Hartge K H (1986). Bulk Density. In: A Klute (Ed.), Methods of Soil Analysis, Part 1. Physical and Mineralogical Methods, Agronomy Monograph No: 9, SSSA, Madison, WI, pp: 363-375, (p: 393)

Bouyoucos G J (1951). A Recalibration of The Hydrometer Method for Making Mechanical Analysis of Soils. Agronomy Journal 43: 434-438

Brown D J (2007). Using A Global VNIR Soil-Spectral Library for Local Soil Characterization and Landscape Modeling in A $2^{\text {nd }}$ Order Uganda Watershed. Geoderma 140: 444-453

Brown D J, Shepherd K D, Walsh M G, Mays M D \& Reinsch T G (2006). Global Soil Characterization with VNIR Diffuse Reflectance Spectroscopy. Geoderma 132 (3-4): 273-290

Brunet D, Barthès B G, Chotte J L \& Feller C (2007). Determination of Carbon and Nitrogen Contents in Alfisols, Oxisols and Ultisols from Africa and Brazil Using NIRS Analysis: Effects of Sample Grinding and Set Heterogeneity. Geoderma 139: 106-117

Chang C W \& Laird D A (2002). Near-Infrared Reflectance Spectroscopic Analysis of Soil C and N. Soil Science 167(2): 110-116

Chang C W, Laird D A, Mausbach M J \& Hurburgh Jr C R (2001). Near-Infrared Reflectance SpectroscopyPrincipal Components Regression Analysis of Soil Properties. Soil Science Society of America Journal 65: $480-490$

Cozzolino D \& Moron A (2003). The Potential of NearInfrared Reflectance Spectroscopy to Analyse Soil 
Chemical and Physical Characteristics. Journal of Agricultural Sciences 140: 65-71

Creaser C S \& Davies A M C (1988). Section 1: NearInfrared Spectroscopy. In Analytical Applications of Spectroscopy. Royal Society of Chemical. London. P: $1-172$

Dalal R C \& Henry R J(1986). Simultaneous Determination of Moisture, Organic Carbon and Total Nitrogen by Near-Infrared Reflectance Spectrophotometry. Soil Science Society of America Journal 50: 120-123

Daniel K W, Tripathi N K \& Honda K (2003). Artificial Neural Network Analysis of Laboratory and in Situ Spectra for The Estimation of Macronutrients in Soils of Lop Buri (Thailand). Australian Journal of Soil Research 41: 47-59

Dematte J A M, Campos R C, Alves M C, Fiorio P R \& Nanni M R (2004). Visible-NIR Reflectance for Soil Evaluation. Geoderma 121: 95-112

Demiralay İ (1993). Toprak Fiziksel Analizleri. Atatürk Üniversitesi, Ziraat Fakültesi Yayınları No: 143, Erzurum

Demirkol C (1984). Geology and Tectonics of The Region South of Çay (Afyon): Geology of The Taurus Belt. In: O Tekeli \& C Göngüoğlu (Eds.), Mineral Research and Exploration Institute, Ankara, pp. 69-75

Fidèncio P H, Poppi R J \& De Andrade J C (2002). Determination of Organic Matter in Soils Using Radial Basis Function Networks and Near-Infrared Spectroscopy. Analytica Chemica Acta 453(1): 125134

Gutnic M, Monod O, Poisson A \& Dumont J F (1979). Geologie des Tourides Occidentales (Turguie). Meine Society Geology France Series, 58-137, pp.112

Günal H, Erşahin S, Akbaş F \& Budak M (2007). Toprak Biliminde Kizıl Ötesi Spektrometrenin Potansiyel Kullanımı. Ondokuz Mayıs Üniversitesi, Ziraat Fakültesi Dergisi 22(2): 219-226

Hizalan E \& Ünal H (1966). Topraklarda Önemli Kimyasal Analizler. Ankara Üniversitesi, Ziraat Fakültesi, Yayın No: 278

Islam K, McBratney A \& Singh B (2005). Rapid Estimation of Soil Variability from The Convex Hull Biplot Area of Topsoil Ultra-Violet, Visible and NearInfrared Diffuse Reflectance Spectra. Geoderma 128: 249-257

Islam K, Singh B \& McBratney A B (2003). Simultaneous Estimation of Several Soil Properties by Ultra-Violet,
Visible and Near-Infrared Reflectance Spectroscopy. Australian Journal of Soil Research 41: 1101-1114

Jackson M L (1958). Soil Chemical Analysis. P: 498. Prentice-Hall, Inc. Englewood Cliffs, New Jersey. USA

Janik L J \& Skjemstad J O (1995). Characterisation and Analysis of Soils Using Mid-Infrared Partial Least Squares: II. Correlations with Some Laboratory Data. Australian Journal of Soil Research 33: 637-650

Janik L J, Merry R H \& Skjemstad J O (1998). Can Mid Infra-Red Diffuse Reflectance Analysis Replace Soil Extractions? Australian Journal of Experimental Agriculture 38(7): 68-696

Karaman M E, Meriç E, Tansel İ (1988). Çünür (Isparta) Dolaylarında Kretase-Tersiyer geçişi. Akdeniz Üniversitesi, Isparta Mühendislik Fakültesi Dergisi, Jeoloji Mühendisiliği Seksiyonu 4: 80-100

Koçyiğit A, Cihan M \& Özacar A (2001). Dombayova ve Sandıklı (Afyon) Grabenlerinin Depremselliği ve Kenar Faylarının, Kinematik Analizi. Tübitak Proje Raporları, Rapor No: YDABÇAG 199Y007, p.69

Koşun E, Sarıgül A \& Varol B (2005). Antalya Tufalarının Litofasiyes Özellikleri. Maden Tetkik Arama Dergisi 130: $57-70$

Masserschmidt I, Cuelbas C J, Poppi R J, De Andrade J C, De Abreu C A \& Davanzo C U (1999). Determination of Organic Matter in Soils by FTIR/Diffuse Reflectance and Multivariate Calibration. Journal of Chemometrics 13: 265-273

McBratney A B, Minasy B \& Viscarra Rossel R (2006). Spectral Soil Analysis and Inference Systems: A Powerful Combination for Solving The Soil Data Crisis. Geoderma 136: 272-278

McCarty G W, Reeves III J B, Reeves V B, Follett R F \& Kimble J M (2002). Mid-Infrared and Near-Infrared Diffuse Reflectance Spectroscopy for Soil Carbon Measurements. Soil Science Society of America Journal 66: 640-646

Minasy B, McBratney A B, Tranter G \& Murphy B W (2008). Using of Soil Knowledge fort The Evaluation of Mid-Infrared Diffuse Reflectance Spectroscopy for Prediction Soil Physical and Mechanical Properties. European Journal of Soil Science 59: 960-971

Moreira C S, Brunet D, Verneyre L S Á S M O, Galdos M V, Cerri C C \& Bernoux M (2009). Near-Infrared Spectroscopy for Soil Bulk Density Assessment. Europen Journal of Soil Science 60: 785-791 
Murray I \& Cowe I A (1992). Making Light Work: Advances in Near-Infrared Spectroscopy. Weinheim, New York, pp. 569

Öncel M S (1995). Şarkikaraağaç-Yalvaç (Isparta) Arasının Jeolojisi ve Boksit Zuhurlarının Mineralojik, Petrografik, Jeokimyasal İncelemesi. Doktora Tezi, Selçuk Üniversitesi Fen Bilimleri Enstitüsü (Basılmamış), Konya

Reeves III J B \& McCarty G W (2001). Quantitative Analysis of Agricultural Soils Using Near-Infrared Reflectance Spectroscopy and Fibre-Optic Probe. Journal of Near-Infrared Spectroscopy 9: 25-34

Reeves III J B, McCarty G W \& Meisinger J J (1999). Near-Infrared Reflectance Spectroscopy for The Analysis of Agricultural Soils. Journal of NearInfrared Spectroscopy 7: 179-193

Schafer W M \& Singer M J (1976). A New Method of Measuring Shrink-Swell Potential Using Soil Pastes. Soil Science Society of America Journal 40: 805-806

Schulling R D (1973). Active Role of Continents in Tectonic Evolution, Geothermal Models. In: De jong, K.A.\&R. Scholten (Eds), Gravite and Tectonics, New York, 37-47

Shepherd K D \& Walsh M G (2002). Development of Reflectance Spectral Libraries for Characterization of Soil Properties. Soil Science Society of America Journal 66: 988-998

Shibusawa S, Imade Anom S W, Sato S, Sasao A \& Hirako S (2001). Soil Mapping Using the Real-Time Soil Spectrophotometer. In: Grenier, G., Blackmore, S. (Eds), ECPA 2001, $3^{\text {nd }}$ European Conference on Precision Agriculture, Vol: 1, Agro Montpellier, Pp: 497-508

Sørensen LK \& Dalsgaard S (2005). Determination of Clay and Other Properties by Near-Infrared Spectroscopy. Soil Science Society of America Journal 69: 159-167

Sudduth K A \& Hummel J W (1991). Evaluation of Reflectance Methods for Soil Organic Matter Sensing. Transactions of The American Society of Agricultural Engineers 34(4): 1900-1909
Şahin N (1997). Yakaavşar (Isparta) - Beyşehir Gölü Arasındaki Bölgenin Stratigrafisi ve Tektonik Özellikleri. Yüksek lisans tezi, Süleyman Demirel Üniversitesi Fen Bilimleri Enstitüsü (Basılmamış), Isparta

The Unscrambler (2010). The Unscrambler User's Guide, Version: 9.7, Woodbridge, N.J., USA: CAMO Software AS (demo)

Viscarra Rossel R A, Walter C \& Fouad Y (2003). Assessment of Two Reflectance Techniques for The Quantification of Field Soil Organic Carbon. In: J Stafford \& A Werner (Eds), Precision Agriculture. $4^{\text {nd }}$ European Conference on Precision Agriculture. Wageningen Academic Publishers, Berlin, pp: 697703

Viscarra Rossel RA, Walvoort D J J, McBratney A B, Janik L J \& Skjemstad J O (2006). Visible, Near-Infrared, Mid-Infrared or Combined Diffuse Reflectance Spectroscopy for Simultaneous Assessment of Various Soil Properties. Geoderma 131: 59-75

Waldron J W F (1984). Stratigraphy and Sedimentary Evolution of The NE Antalya Complex: Isparta Province, Turkey. Bulletin of The Mineral Research and Exploration Institute of Turkey, 97/98, 1-20

Walvoort D J J \& McBratney A B (2001). Diffuse Reflectance Spectrometry as A Proximal Sensing Tool for Precision Agriculture. In: Grenier, G., Blackmore, S. (Eds), ECPA 2001, $3^{\text {nd }}$ European Conference on Precision Agriculture, Vol: 1, Agro Montpellier, pp: 503-507

Wetzel D L (1983). Near-Infrared Reflectance Analysis. Sleeper Among Spectroscopic Techniques. Analytical Chemistry 55: 1165A-1176

Workman J Jr (1996). Interpretive Spectroscopy for NearInfrared. Applied Spectroscopy 3: 251-320

Zornoza R, Guerrero C, Mataix-Solera J, Scow K M, Arcenegui V \& Mataix-Beneyto J (2008). NearInfrared Spectroscopy for Determination of Various Physical, Chemical and Biochemical Properties in Mediterranean Soils. Soil Biology and Biochemistry 40: $1923-1930$ 